Check for updates

Cite this: RSC Adv., 2020, 10, 13155

Received 12th February 2020

Accepted 24th March 2020

DOI: 10.1039/d0ra01362e

rsc.li/rsc-advances

\section{Modification of fibrous membrane for organic and pathogenic contaminants removal: from design to application $\dagger$}

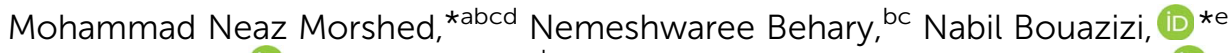 \\ Julien Vieillard, (D) ${ }^{\text {e }}$ Jinping Guan, ${ }^{d}$ Franck Le Derf ${ }^{\mathrm{e}}$ and Vincent Nierstrasz (D)
}

In this study, a flexible multifunctional fibrous membrane for heterogeneous Fenton-like removal of organic and pathogenic contaminants from wastewater was developed by immobilizing zerovalent iron nanoparticles (Fe-NPs) on an amine/thiol grafted polyester membrane. Full characterization of the resulting polyester membranes allowed validation of successful grafting of amine/thiol $\left(\mathrm{NH}_{2}\right.$ or $\left.\mathrm{SH}\right)$ functional groups and immobilization of Fe-NPs $(50-150 \mathrm{~nm})$. The Fenton-like functionality of iron immobilized fibrous membranes (PET-Fe, $\mathrm{PET}-\mathrm{Si}-\mathrm{NH}_{2}-\mathrm{Fe}, \mathrm{PET}-\mathrm{NH}_{2}-\mathrm{Fe}$, and PET-SH-Fe) in the presence of hydrogen peroxide $\left(\mathrm{H}_{2} \mathrm{O}_{2}\right)$ was comparatively studied in the removal of crystal violet dye (50 $\mathrm{mg} \mathrm{L}^{-1}$ ). The effect of $\mathrm{pH}$, amount of iron and $\mathrm{H}_{2} \mathrm{O}_{2}$ concentration on dye removal was systematically investigated. The highest dye removal yield reached $98.87 \%$ in $22 \mathrm{~min}$ at a rate constant $0.1919 \mathrm{~min}^{-1}\left(R^{2}=95.36\right)$ for PET-SH-Fe providing $78 \%$ toxicity reduction assessed by COD analysis. These membranes could be reused for up to seven repeated cycles. Kinetics and postulated mechanism of colour removal were proposed by examining the above results. In addition, the resultant membranes showed substantial antibacterial activity against pathogenic bacteria (Staphylococcus epidermidis, Escherichia coli) strains studied through disc diffusion-zone inhibitory and optical density analysis. These findings are of great importance because they provide a prospect of textile-based flexible catalysts in heterogeneous Fenton-like systems for environmental and green chemistry applications.

\section{Introduction}

With the decrease of freshwater resources, the recovery of water from wastewater is increasingly important for the sustainable development of the world. Extensive industrialization and a continuous discharge of massive amount of wastewater cause the utmost distress for biodiversity as well as public health. ${ }^{\mathbf{1 - 4}}$ Among different types of toxicants (such as-dyes, phenols, bacteria, and nitro-aromatic compounds), aromatic dyes and pathogenic bacteria receive the highest concern due to their availability, high toxic nature, bioaccumulation, chemical

${ }^{a}$ Textile Materials Technology, Department of Textile Technology, The Swedish School of Textiles, Faculty of Textiles, Engineering and Business, University of Borås, SE-50190, Borås, Sweden.E-mail: mohammad_neaz.morshed@hb.se

${ }^{b}$ Ecole Nationale Supérieure des Arts et Industries Textiles (ENSAIT), GEMTEX Laboratory, 2 allée Louise et Victor Champier BP 30329, 59056 Roubaix, France 'Université de Lille, Nord de France, F-59000 Lille, France

${ }^{d}$ College of Textile and Clothing Engineering, Soochow University, 215006 Suzhou, China

${ }^{e}$ Normandie Université, COBRA, UMR 6014 and FR3038, Université de Rouen, INSA Rouen, CNRS, 55, Rue Saint Germain, 27000 Evreux, France. E-mail: bouazizizi. nabil@hotmail.fr

$\dagger$ Electronic supplementary information (ESI) available. See DOI: 10.1039/d0ra01362e stability and resistance to conventional treatment methods., ${ }^{\mathbf{1 , 5 , 6}}$ Among various water remediation technologies, advanced oxidation processes (AOPs), which are based on the generation of reactive oxygen species (ROS), are regarded as an effective technology for the degradation of hazardous organic pollutants in wastewater. ${ }^{7-13}$ Fenton and Fenton-like treatments are best due to their high degradation ability, range of applicability and cost-effectiveness. ${ }^{\mathbf{1 4 - 1 7}}$ However, homogeneous Fenton-like degradation processes containing free reagents (iron ions and hydrogen peroxide) have some critical disadvantages, which is unacceptable for commercial applications such as selective reaction conditions (acidic $\mathrm{pH}$ ), generation of iron sludge and single-use reagent is a costly and counterproductive procedure. Therefore, much effort has been invested to improve the treatment efficiency of the Fenton reaction process as well as extending their working conditions and cutting down on secondary pollution.

Heterogeneous Fenton reaction using solid immobilized iron (zerovalent iron nanoparticles) has gained attention for degradation of various types of complex pollutants providing the prospects of reducing the consumption of iron and reusability of iron as well as functioning reactor in a commercially operable reaction condition. Our previous studies reported the effectiveness of zerovalent iron nanoparticles towards 
detoxification of water containing aromatic dyes, ${ }^{\mathbf{1 2 , 1 8 , 1 9}}$ phenolic compounds, ${ }^{20,21}$ and bacteria strains. ${ }^{18}$ However, considerable improvement is still necessary due to unsatisfactory activity in terms of leaching and easy oxidation of iron nanoparticles as well as in using fatal reducing agents (sodium borohydride) and discount in total detoxification of the pollutants.

Unlike other support materials, very few works of literature have been found where flexible material such as textile fibres or membranes were used to immobilize iron nanoparticles aiming at heterogeneous catalytic applications. Iron immobilized on PAA, ${ }^{12,22}$ starch, ${ }^{23}$ and polyglycol ${ }^{24}$ reported in different literature to treat contaminants. However, to avoid secondary water contamination, the immobilization of zerovalent iron nanoparticles onto solid supports (for example, polymeric membranes ${ }^{25}$ and activated carbon, ${ }^{26}$ ) could be ideal.

Polyester membrane-PET (a flexible, porous, recyclable, nontoxic, biocompatible material with resistance to most chemical substances and microorganism) has successfully described as a feasible support material to immobilize various organic and inorganic catalyst and it demonstrated to have increased stability and to allow mobility of materials. ${ }^{27}$ Since the polyester surface is hydrophobic and non-interactive to most organicinorganic substances, surface activation of the PET membrane is necessary. Among many surface activation processes ${ }^{28-30}$ of polyester, plasma treatment is more desirable due to their costeffectiveness and eco-friendliness (no harmful solvent, no chemical waste and less destruction of the specimen). Frédéric L. et al. (2009) ${ }^{31}$ reported that surface activation of polyester by air atmospheric plasma treatment introduces hydrophilic surface functional groups such as $-\mathrm{OH},-\mathrm{COOH}$. While Alenka V. et al. $(2008)^{32}$ earlier reported the formation of amine and amide functional groups on polyester surface treated by nitrogen plasma. Our previous study reported the insight of air-atmospheric plasma treatment for surface activation of the polyester membrane ${ }^{33}$ and the loading of iron nanoparticles on amine/thiol grafted polyester membrane for catalytic reduction of methylene blue and 4-nitrophenol in water.

Although several studies reported the realization of immobilized catalysts for Fenton-like removal of toxic pollutants, ${ }^{34-36}$ to our best knowledge, no study has reported the heterogeneous Fenton like (oxidative) removal of organic and pathogenic contaminants using flexible fibrous membrane prepared by immobilizing of Fe-NPs on amine/thiol grafted polyester membrane. Herein, this study reports heterogeneous Fentonlike (oxidative) removal of crystal violet dye and inhibition of the growth of Gram-positive Staphylococcus epidermidis (ATCC 12228) and Gram-negative Escherichia coli (ATCC 25922) bacteria strains by using such modified fibrous membrane. For that, the polyester surface was activated by air atmospheric plasma treatment followed by chemical grafting of polyamidoamine dendrimer or 3-(aminopropyl)-triethoxysilane or 1-thioglycerol before in situ reduction-immobilization of Fe-NPs. The resultant fibrous membranes were characterized by using SEM, FT-IR spectroscopy, TGA, DSC, wettability and optical microscopy. The mechanism of the catalytic properties, influencing factors as well as reusability of the membrane has been discussed. The antibacterial activity of prepared membranes was evaluated through disc diffusion and zone inhibitory as well as optical density analysis towards both bacteria strains individually and mixed.

\section{Experimental}

\subsection{Chemicals}

3-(Aminopropyl)-triethoxysilane (APTES); poly-(amidoamine)$\left(\mathrm{NH}_{2}\right)_{4}$ dendrimer (PAMAM); 1-thioglycerol (SH); absolute ethanol (Et-OH); hydrogen peroxide $\left(\mathrm{H}_{2} \mathrm{O}_{2}\right) ; \mathrm{Fe}(\mathrm{NO})_{3}$ and sodium tetrahydroborate $\left(\mathrm{NaBH}_{4}\right)$ were purchased from Sigma Aldrich Ltd and used as received without any further purification (Fig. 1). Deionized water from a water purification system provided by GFL-Gesellschaft für Labortechnik mbH (Germany) was used throughout all the experiments. PET nonwoven of thickness- $950 \mu \mathrm{m}$, an areal density of $230 \mathrm{~g} \mathrm{~m}^{-2}$, a porosity of $93 \%$, and an air-permeability of $645 \mathrm{~mm} \mathrm{~s}^{-1}$ was spun in European nonwoven platform, CENT (France) based on web of fibres (avg. diameter $12 \mu \mathrm{m}$ ) formed by carding and consolidated by hydro-entanglement (entangling with water jets).

\subsection{Plasma treatment and chemical grafting of PAMAM, APTES, and SH on polyester membrane}

Surface impurities in polyester membranes such as dust, spinning oil and contaminants were extracted by using a Soxhlet extraction method as described in our previous studies..$^{37,38}$ The removal of impurities was assessed by the water break test where surface tension of sample water (from PET rinsing bath) was compared with freshwater $\left(72.6 \mathrm{mN} \mathrm{m}^{-1}\right) .{ }^{39}$ After that, twosteps surface modification of polyester membranes was conducted before the immobilization of iron particles. In the first step, air atmospheric plasma treatment was used to activate the hydrophobic surface of polyester and in a second step,

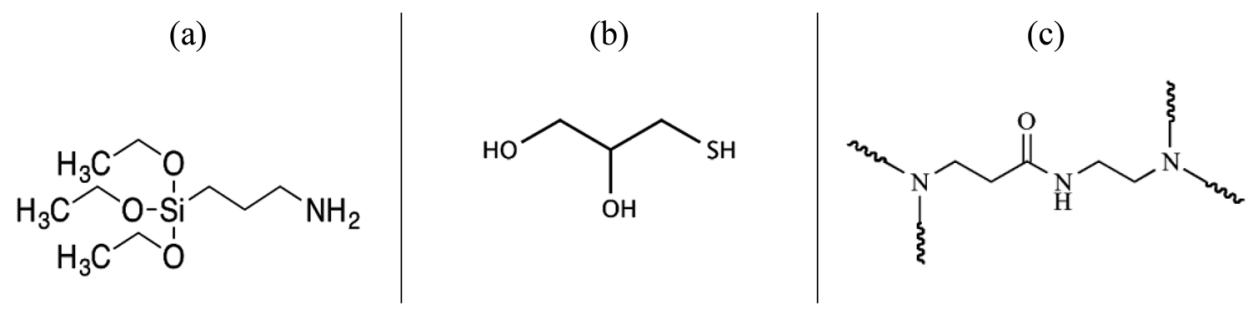

Fig. 1 Chemical structure of (a) 3-(aminopropyl)-triethoxysilane, (b) 1-thioglycerol and (c) repeating unit of poly-(amidoamine)-( $\left.\mathrm{NH}_{2}\right)_{4}$ dendrimer. 
incorporation of PAMAM, APTES, and $\mathrm{SH}$ on plasma-treated membranes as explained below;

(i) Air atmospheric plasma treatment was carried in plasma treatment setup at École Nationale supérieure des arts et industries textiles (ENSAIT) provided by Ahlbrandt System (Germany). The device is equipped with a roll-shaped electrode along with two other counter electrodes (inter-electrode distance is $1.5 \mathrm{~mm}$ ) in an atmospheric air condition having a glow discharge instigated by the potential difference termed the DBD-Dielectric Barrier Discharge as described in our previous reports. ${ }^{37,40}$ The treatment was done continuously on both sides at a constant speed of $2 \mathrm{~m} \mathrm{~min}^{-1}$ under $750 \mathrm{w}$ electrical power. Plasma treatment modifies the hydrophobic surface of polyester into hydrophilic by introducing hydroxyl and carboxylic terminal groups as illustrated in Fig. 2a.

(ii) Secondly, the freshly activated polyester membrane was prone to chemical grafting of PAMAM, APTES and SH using ethanol/water $(3: 1 \mathrm{v} / \mathrm{v})$ as the solvent. PAMAM and APTES $(0.3 \mathrm{wt} \%)$ was grafted under constantly stirring for $4 \mathrm{~h}$ at $70{ }^{\circ} \mathrm{C}$ in atmospheric air and nitrogen $\left(\mathrm{N}_{2}\right)$ chamber, respectively. Following the same protocol, $\mathrm{SH}$ was also grafted in a separate plasma-treated membrane in an $\mathrm{N}_{2}$ chamber under constant stirring for $12 \mathrm{~h}$. The resulting materials denoted PET-
$\mathrm{NH}_{2} \mid$ PET-Si-NH $\mathrm{N}_{2} \mid$ PET-SH (see Fig. 2b-d), were washed filtrated and then dried at $60{ }^{\circ} \mathrm{C}$ overnight.

\subsection{Immobilization of Fe-NPs on polyester membrane}

Zerovalent iron nanoparticles (Fe-NPs) was immobilized on PET (plasma treated) $\left|\mathrm{PET}-\mathrm{NH}_{2}\right| \mathrm{PET}-\mathrm{Si}-\mathrm{NH}_{2} \mid \mathrm{PET}-\mathrm{SH}$ through the in situ reduction-immobilization method. Typically, $\mathrm{Fe}(\mathrm{NO})_{3}$ (0.6 wt\%) was dispersed in $\mathrm{H}_{2} \mathrm{O}$ along with $1.0 \mathrm{wt} \%$ functionalized membrane and stirred for $1 \mathrm{~h}$ at room temperature to create complex between Fe-ions and terminal functional groups of each functionalized membrane. After that, $\mathrm{NaBH}_{4}(0.9 \mathrm{mM})$ as a reducing agent was added and allowed the reduction of iron ions into zerovalent iron nanoparticles during $4 \mathrm{~h}$ under constant stirring. Obtained PET-Fe, PET-NH ${ }_{2}-\mathrm{Fe}, \mathrm{PET}-\mathrm{Si}-\mathrm{NH}_{2}-$ $\mathrm{Fe}$, and PET-SH-Fe (see Fig. $2 \mathrm{e}-\mathrm{g}$ ) was vacuum dried (at $60^{\circ} \mathrm{C}$ ) and stored in $\mathrm{O}_{2}$-free desiccator.

\subsection{Material characterizations}

Surface morphology of treated and untreated polyester membranes was observed by scanning electron microscope (SEM) using ZEISS EVO15 and MEB HR ZEISS Sigma 300 electron microscope. Before imaging, all samples were metalized by
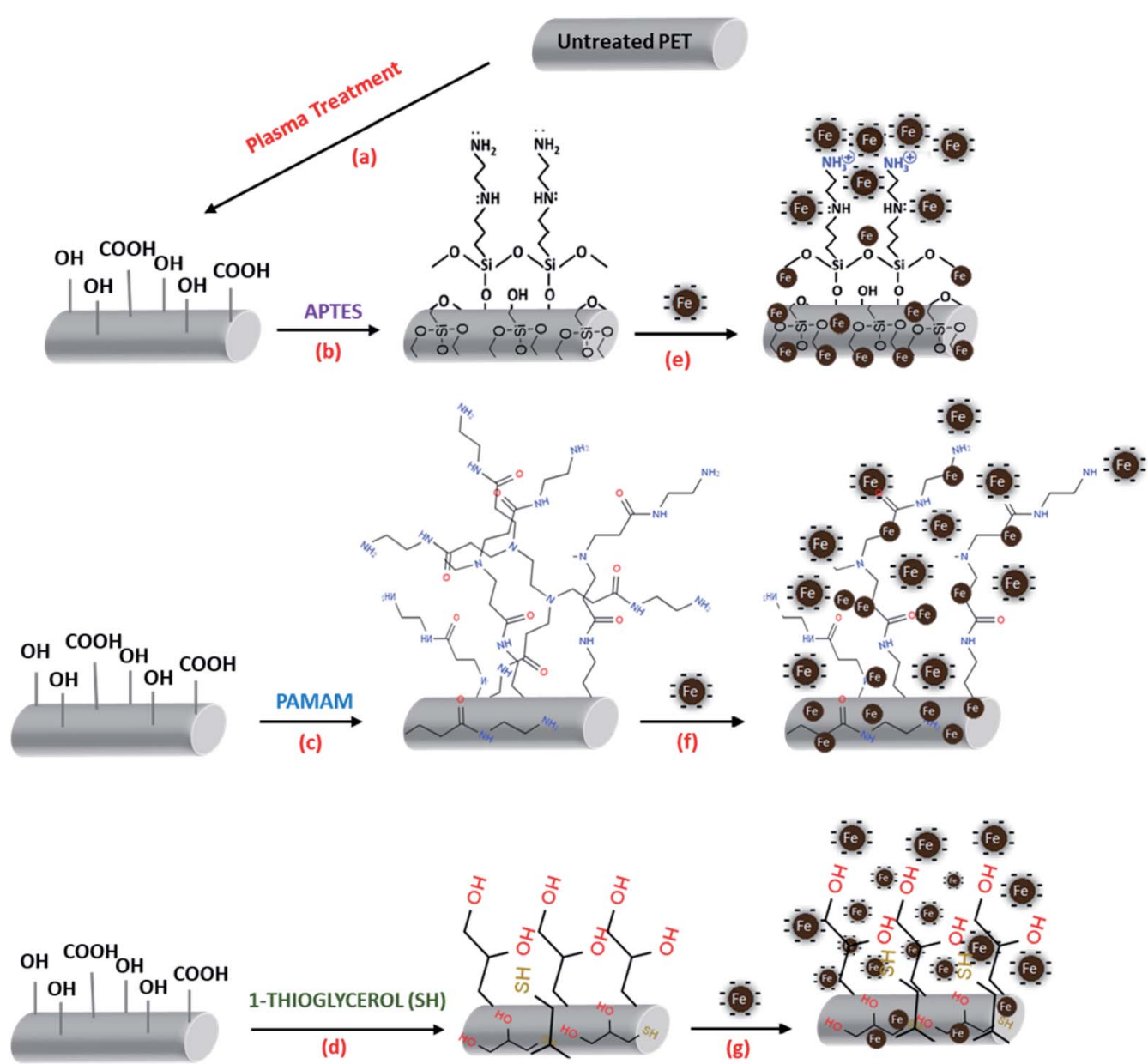

Fig. 2 Schematic illustration of (a) plasma treatment of PET, chemical grafting of (b) APTES, (c) PAMAM, (d) 1-thioglycerol (SH) on plasma-treated polyester and in situ reduction-immobilization of zerovalent Fe-NPs on (e) APTES, (f) PAMAM, (g) SH grafted PET. 
conductive materials (gold) using Biorad E5200 device. Average fibre diameter and particle size of materials were investigated from HR-SEM images using image analysis software (ImageJ 1.40G), as described in our previous studies ${ }^{\mathbf{1 2}}$ and obtained standard deviation and corresponding size distribution histograms. Triplicate static contact angle measurements of polyester nonwovens before and after surface modifications were carried out through sessile droplet goniometry using Attension Theta Optical Tensiometer (Biolin Scientific) according to the method explained in Section 1.1 of ESI. $\dagger$ Changes of surface functional groups after APTES, PAMAM and $\mathrm{SH}$ incorporation were identified by Fourier transform infrared spectroscopy (FTIR) analysis using Thermo Scientific ${ }^{\mathrm{TM}}$ Nicolet $^{\mathrm{TM}}$ iS $^{\mathrm{TM}} 10$ FTIR Spectrometer. The spectra were measured between the wavenumber $4000-400 \mathrm{~cm}^{-1}$ where background spectra were measured in air. The functional groups' identification was carried out by using OMNIC Specta Software. Comparative thermal behaviour and quantitative iron content on ironimmobilized membranes were studied by differential scanning calorimetry (DSC) and thermogravimetric analysis (TGA), respectively using TG-DTA, A6300R instrument under nitrogen $\left(\mathrm{N}_{2}\right)$ medium.

\subsection{Heterogeneous Fenton-like removal of crystal violet dye}

Performance of polyester fibrous membranes (PET-Fe|PET-Si$\mathrm{NH}_{2}-\mathrm{Fe}\left|\mathrm{PET}-\mathrm{NH}_{2}-\mathrm{Fe}\right| \mathrm{PET}-\mathrm{SH}-\mathrm{Fe}$ ) in oxidative (heterogeneous Fenton-like) removal of crystal violet dye in the presence of hydrogen peroxide $\left(\mathrm{H}_{2} \mathrm{O}_{2}\right)$ was studied. The effect of $\mathrm{pH}$, amount of $\mathrm{Fe}$ and $\mathrm{H}_{2} \mathrm{O}_{2}$ concentration on the removal of dye was systematically investigated. The quantitative analysis was recorded by using UV-visible spectrophotometer.

In a typical removal reaction, a $3.0 \mathrm{~mL}$ dye solution (50 mg. $\mathrm{L}^{-1}$ ) in a quartz cuvette was treated by using $1 \mathrm{~cm}^{2}$ iron immobilized polyester membrane $(\sim 30 \mathrm{mg})$ and $500 \mu \mathrm{L} \mathrm{H}_{2} \mathrm{O}_{2}$ $(0.3 \mathrm{M})$ at $\mathrm{pH} 5$ (temperature $T=25^{\circ} \mathrm{C}$ ). The presence of $\mathrm{Fe}$ and $\mathrm{H}_{2} \mathrm{O}_{2}$ immediately initiated the Fenton reaction that produces high oxidation potential radicles $(\cdot \mathrm{HO})$. In a secondary rapid and exothermic reaction, $\cdot \mathrm{HO}$ oxidizes crystal violet dye into primarily carbon dioxide and water (colourless). The instant-toinitial absorbance ratio of dye solution $\left(A_{t} / A_{0}\right)$ was measured at different time intervals. The changes in absorption indicate the removal of dye, which later calculated using eqn (1).

$$
\operatorname{Removal}(\%)=\frac{C_{0}-C_{t}}{C_{0}} \times 100
$$

Here, $C_{0}$ is the initial concentration of crystal violet, and $C_{t}$ represents the concentration of crystal violet at different time intervals during removal.

After complete removal of the dyes, the nonwoven fibrous membrane was removed from the solution, rinsed through a continuous flow of distilled water before reuse for another cycle application. The consecutive reuse of the membranes was studied under identical experimental conditions.

2.5.1. Effect of $\mathbf{p H}$ on dye removal performance. The effect of $\mathrm{pH}(3,5,7$, and 9$)$ on dye removal performance as a function of time were studied. All removal experiments were carried out for $3.0 \mathrm{~mL}\left(50 \mathrm{mg} . \mathrm{L}^{-1}\right)$ dye solution mounted in a quartz cuvette where $1 \mathrm{~cm}^{2}$ iron-immobilized polyester membrane and $500 \mu \mathrm{L}$ $\mathrm{H}_{2} \mathrm{O}_{2}(0.3 \mathrm{M})$ were used.

2.5.2. Effect of amount iron on dye removal performance. The effect of the amount of iron on removal efficiency using iron-immobilized polyester membrane was examined. All the experiments were carried out at room temperature and in $\mathrm{pH} 5$ for $3.0 \mathrm{~mL}$ dye solution mounted in a quartz cuvette where 1 $\mathrm{cm}^{2}$ iron-immobilized polyester membrane and $500 \mu \mathrm{L} \mathrm{H}_{2} \mathrm{O}_{2}$ (0.3 M) were used.

2.5.3. Effect of $\mathrm{H}_{2} \mathrm{O}_{2}$ concentration on dye removal performance. Different concentration of $\mathrm{H}_{2} \mathrm{O}_{2}(100,300,500$ and $700 \mu \mathrm{L}$ ) on dye removal performance was investigated. All the experiments were carried out at room temperature and in $\mathrm{pH} 5$ where $1 \mathrm{~cm}^{2}$ iron-immobilized polyester membrane and $3 \mathrm{~mL}$ (50 $\mathrm{mg} \mathrm{L}^{-1}$ ) dye solution mounted in a quartz cuvette was used.

2.5.4. Toxicity reduction study. Decoloration of dye doesn't guarantee the detoxification of polluted water. Therefore, we studied the detoxification of water after the removal process in terms of chemical oxygen demand (COD) analysis. Typically, the chemical oxygen demand of treated and untreated water studied as per "ASTM D1252-06-chemical oxygen demand (dichromate oxygen demand) of water" test method B using COD vials provided by CHEMetrics, Inc. (USA) where the final COD was calculated using eqn (2) as similar to the method reported earlier ${ }^{18,40}$

$$
\operatorname{COD}\left(\mathrm{mg} \mathrm{L}^{-1}\right)=\left(23010 \times \Delta_{620}\right) \times 3
$$

Here, $\Delta_{620}$ represents the absorption difference (at $\lambda_{620 \mathrm{~nm}}$ ) of the vials after the digestion of water sample at $150{ }^{\circ} \mathrm{C}$ for $2 \mathrm{~h}$.

The result stated as parts per million $\left(\mathrm{mg} \mathrm{L}^{-1}\right)$. COD reduction was studied over time until maximum decolouration was achieved.

\subsection{Antibacterial activity study}

The antibacterial activity of iron-immobilized polyester membranes was evaluated through disc diffusion and zone inhibitory as well as optical density analysis towards Grampositive Staphylococcus epidermidis (ATCC 12228) and Gramnegative Escherichia coli (ATCC 25922) bacteria strains according to the method explained elsewhere ${ }^{\mathbf{1 8}}$. The antibacterial behaviour was measured on individual bacteria as well as in a bacteria mixture solution.

Mueller Hinton agar plates were used for diffusion and zone inhibition analysis. The test is a semi-quantitative method where the antibacterial activity was assessed by examining the absence or presence of microbial growth in the contact zone between agar and specimen and on the eventual appearance of an inhibition zone according to ISO 20645. The membrane with $1 \mathrm{~cm}^{2}$ was placed on the surface of nutrient agar medium, which was swabbed with the bacterial $\left(10^{6} \mathrm{cfu}^{-3}\right)$ culture. The plates were incubated at $37^{\circ} \mathrm{C}$ for $24 \mathrm{~h}$ to measure the zone of inhibition in millimetres formed around the membrane. The results were expressed as the width of the inhibition zone ( $\mathrm{mm}$ ).

The inhibition of $E$. coli and $S$. epidermidis bacteria mix were also calculated by measuring the optical density at $630 \mathrm{~nm}$ using a UV-visible spectrophotometer at room temperature. ${ }^{18}$ 
Kinetics of antibacterial property of the membranes towards the mixture of Gram-positive and Gram-negative bacteria strains were studied as well.

\section{Results and discussions}

The results were presented and discussed in two separate parts where the first part focuses on the analysis of polyester membranes before and after PAMAM, APTES and SH grafting and iron immobilization. The second part confers the catalytic behaviour of prepared iron-immobilized polyester membrane towards the removal of toxic dye (crystal violet) and inhibition of Gram-positive (Staphylococcus epidermidis) and Gram-negative (Escherichia coli) bacteria strains. Table 1 describes the sample terminology and their corresponding treatment used in this study.

Table 1 Sample terminology

\begin{tabular}{ll}
\hline Sample terminology & Treatments \\
\hline Untreated PET & Raw polyester nonwoven membrane (without any treatment) \\
PET & Plasma treatment \\
PET- $\mathrm{NH}_{2}$ & Plasma treatment + PAMAM dendrimer grafting \\
PET-Si- $\mathrm{NH}_{2}$ & Plasma treatment + APTES grafting \\
PET-SH & Plasma treatment + 1-thioglycerol grafting \\
PET-Fe & Plasma treatment + Fe immobilization \\
PET- $-\mathrm{NH}_{2}-\mathrm{Fe}$ & Plasma treatment + PAMAM dendrimer grafting + Fe immobilization \\
PET-Si- $\mathrm{NH}_{2}-\mathrm{Fe}$ & Plasma treatment + APTES grafting + Fe immobilization \\
PET-SH-Fe & Plasma treatment + 1-thioglycerol grafting + Fe immobilization
\end{tabular}

a. Untreated polyester Membrane $\left(\theta_{\mathrm{H} 2 \mathrm{O}}\right.$

$$
\left.=137^{\circ}\right)
$$

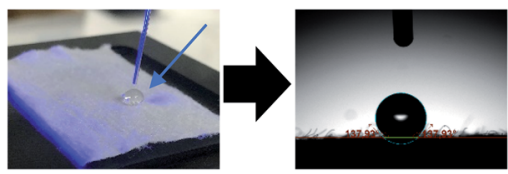

b. Plasma treated polyester membrane

$$
\left(\theta_{\mathrm{H} 2 \mathrm{O}}=0^{0}\right)
$$

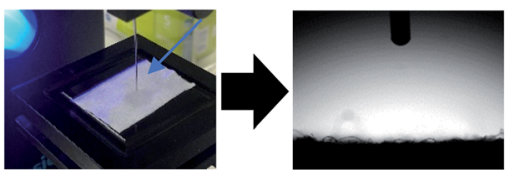

Fig. 3 Water contact angle analysis of (a) untreated and (b) plasma-treated polyester membrane using sessile droplet goniometry (digital image and fitting semicircle).
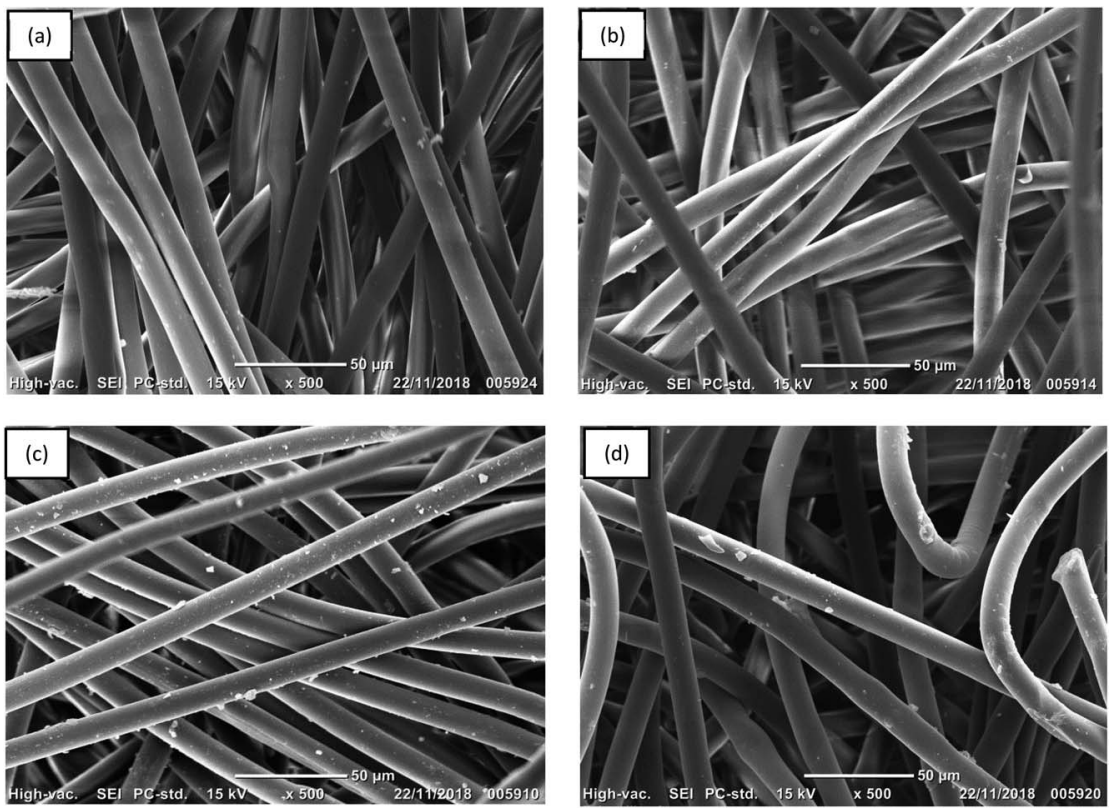

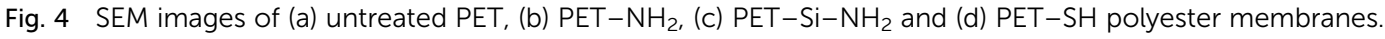


3.1. Part 1: analysis of polyester nonwoven membrane before and after PAMAM, APTES and SH grafting and iron immobilization.

3.1.1. Analysis of plasma treatment of polyester membrane. The behaviour of a sessile water droplet deposited at the nonwoven surface was studied to measure the water contact angle $\left(\theta_{\mathrm{H}_{2} \mathrm{O}}\right)$ of the polyester surface before and after plasma treatment. The water contact angle was as high as $137^{\circ}$ at the surface of the untreated polyester membrane (see Fig. 3a), which is higher than that of standard polyester fibre surface $\left(\theta_{\mathrm{H}_{2} \mathrm{O}}=80^{\circ}\right)$. The high surface roughness due to irregularities of the membrane surface would account for such a high water contact angle. However, it is further found that, upon plasma

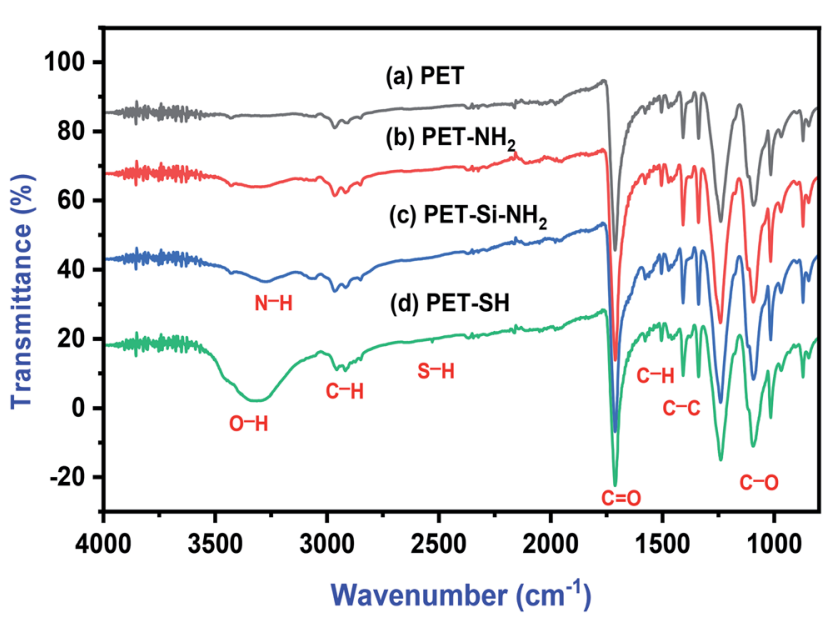

Fig. 5 FTIR spectra of amine/thiol grafted polyester membranes (a) PET, (b) PET-NH ${ }_{2}$, (c) PET-Si-NH $\mathrm{NH}_{2}$ and (d) PET-SH. treatment, the droplet was immediately absorbed (see Fig. 3b), and $\theta_{\mathrm{H}_{2} \mathrm{O}}$ was found at $0^{\circ}$. Our previous studies explained the formation of hydroxyl and carboxylic groups on the polyester surface after plasma treatment using the same set-up through various analysis techniques includes; capillary uptake, Fourier transform infrared spectroscopy, energy dispersive spectroscopy and X-ray photoelectron spectroscopy. ${ }^{37,39,40}$ All the results clearly correlated to the analysis of sessile water droplet test.

3.1.2. Analysis of chemical grafting of PAMAM, APTES and SH on polyester membrane. Plasma treated polyester membrane were prone to chemical grafting of polyamidoamine (PAMAM) dendrimer, 3-(aminopropyl)-triethoxysilane (APTES) or 1-thioglycerol (SH). SEM images in Fig. 4 shows a random network of polyester fibres, where a fairly smooth surface morphology of fibres was observed in untreated PET (see Fig. 4a) but a distribution of white-like grains on other samples has been observed, that can be due to grafting of PAMAM, APTES and SH on the fibres of nonwoven (see Fig. 4b-d). Since SEM analysis does not conclusively validate the claim of the surface modification, Fourier transform infrared spectroscopy has been carried out to identify the chemical changes due to grafting of PAMAM. APTES and SH on the polyester membrane.

FTIR spectra of all samples are shown in Fig. 5. Strong peaks of ether (712-1242 $\left.\mathrm{cm}^{-1}\right)$, carboxyl and carbonyl groups (1650$1712 \mathrm{~cm}^{-1}$ ) were observed on spectra for all samples. Peak present in all samples at $1712 \mathrm{~cm}^{-1}$ is the stretching vibration of $\mathrm{C}=\mathrm{O}$ of the carbonyl group in ester. ${ }^{41}$ The band at $1410 \mathrm{~cm}^{-1}$ and $1577 \mathrm{~cm}^{-1}$ is represented to the $\mathrm{C}-\mathrm{C}$ and $\mathrm{C}-\mathrm{H}$ bond stretching vibration of the phenyl ring. The band at $1239 \mathrm{~cm}^{-1}$ and $1095 \mathrm{~cm}^{-1}$ is due to $\mathrm{C}-\mathrm{O}$ stretching. ${ }^{42}$ Asymmetrical and symmetrical stretching of $\mathrm{CH}_{2}$ and $\mathrm{CH}_{3}$ appeared at $2951 \mathrm{~cm}^{-1}$ and $2848 \mathrm{~cm}^{-1}$ respectively. The characteristics peak near
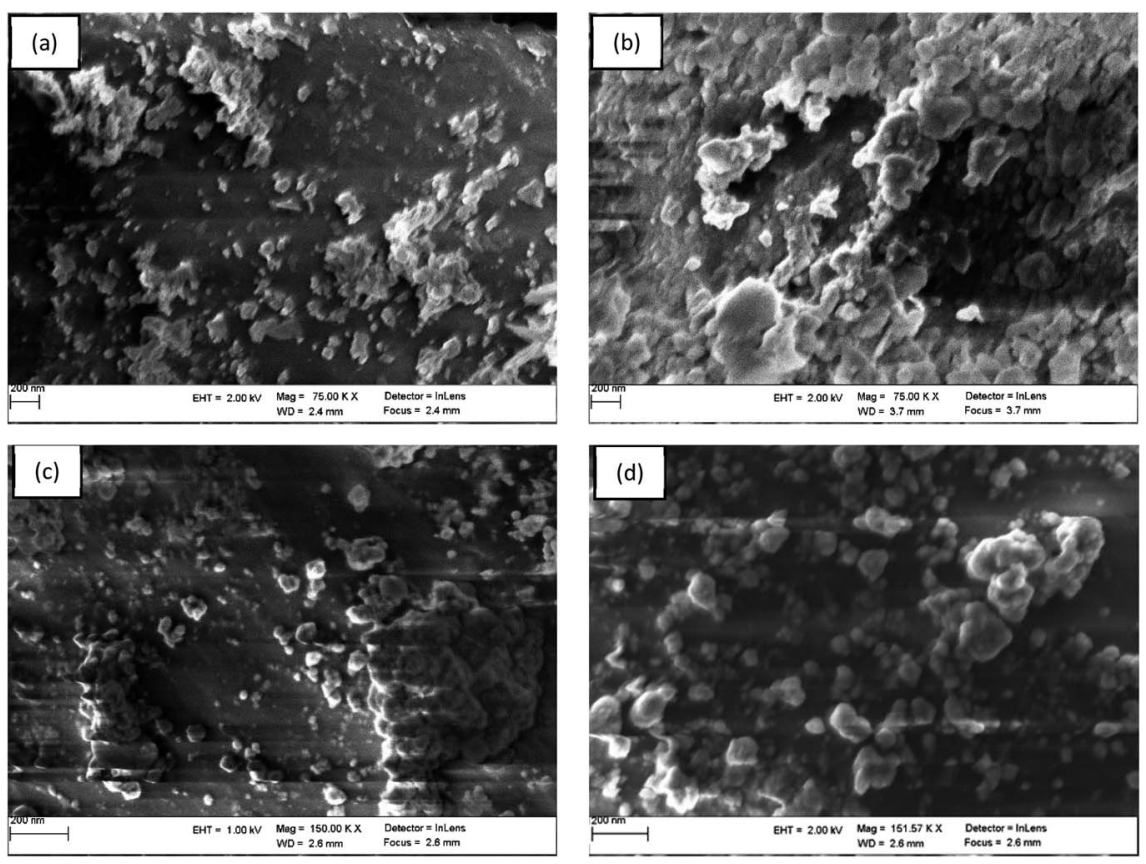

Fig. 6 HR-SEM images of (a) PET-Fe; (b) PET-NH $2-F e$; (c) PET-Si-NH $\mathrm{N}_{2}-\mathrm{Fe}$ and (d) PET-SH-Fe. 
$3428 \mathrm{~cm}^{-1}$ in all samples can be due to $\mathrm{O}-\mathrm{H}$ stretching vibration due to the presence of hydrophilic groups (resulting during plasma treatment).

After surface modification of the polyester with PAMAM, APTES or Thiol, new peaks appeared around $3100 \mathrm{~cm}^{-1}$ to $3700 \mathrm{~cm}^{-1}$ region. The high intensity and clear peaks around $3400-3200 \mathrm{~cm}^{-1}$ corresponds to the primary amino groups $\left(-\mathrm{NH}_{2}\right)^{43}$ (see spectra b, c) is absent in the FTIR spectrum of polyester (spectra a) confirms the presence of PAMAM and APTES. On the other hand, the prominent broad band around $3600-3000 \mathrm{~cm}^{-1}$ (see spectra d) and a minuscule vibration band at $2535 \mathrm{~cm}^{-1}$ corresponds to $\mathrm{O}-\mathrm{H}$ and $\mathrm{S}-\mathrm{H}$ of 1 -thioglycerol ${ }^{44}$ which was not observed in any other sample. This confirms the successful grafting of amine/thiol groups on the polyester membrane.

3.1.3. Analysis of immobilization of Fe-NPs on polyester membrane. Surface morphologies of polyester membranes after immobilization of Fe-NPs has been investigated through scanning electron microscopy (SEM). Changes in fibre diameter, particles size of iron has been studied from SEM images through image processing software (ImageJ). SEM images in Fig. 6 shows the presence of iron particle dispersed over the surface of all polyester membranes (PET-Fe; PET-NH $\mathrm{N}_{2}-\mathrm{Fe}$; PET$\left.\mathrm{Si}-\mathrm{NH}_{2}-\mathrm{Fe} ; \mathrm{PET}-\mathrm{SH}-\mathrm{Fe}\right)$. This visual evidence provides the proof of successful immobilization of iron nanoparticles on the fibre surface. However, a close look at images reveals that individual pre-treatment of polyester fabric before iron immobilization resulted in variation in dispersion, size and stability of the iron particles. The size distribution histogram of the iron particles (see Fig. 7) shows an irregular distribution of iron particles with an average size ranges from 50-150 $\mathrm{nm}$. Given the inverse relationship between size and the dispersion of the particles, aggregation of several small particles into one big particle can be the cause for bigger particle size in samples. Aggregation of particles indicates the stability of the particles. Analysis of individual samples reveals that finest $49 \pm 17 \mathrm{~nm}$ size of iron particles were deposited on PET-SH-Fe sample, indicates less agglomeration of nanoparticles and better stability compared to others, such as PET-Fe (96 $\pm 23 \mathrm{~nm})$, PET-Si-NH ${ }_{2}-\mathrm{Fe}(57 \pm 23 \mathrm{~nm})$ and PET-NH $\mathrm{N}_{2}-\mathrm{Fe}(134 \pm 58 \mathrm{~nm})$.

On the other hand, studies to investigate the changes in fibre diameter due to the immobilization of the iron particles reveals that there was a momentous increase in fibre diameter due to the deposition of the iron particles. A swipe 9.6\% (135 nm) increase in fibre diameter was observed in PET- $\mathrm{NH}_{2}-\mathrm{Fe}$ (see Fig. S3a-d of ESI $\dagger$ ). Since the amount of catalysts plays a significant role in catalytic performance. Along with qualitative validation of iron immobilization, a quantitative analysis of the amount of Fe-NPs deposited on PET-Fe, PET-Si-NH ${ }_{2}-\mathrm{Fe}$, PET- $\mathrm{NH}_{2}-\mathrm{Fe}$, and PET-SH-Fe were studied through thermogravimetric analysis (see Fig. S4 of ESI $\dagger$ ).
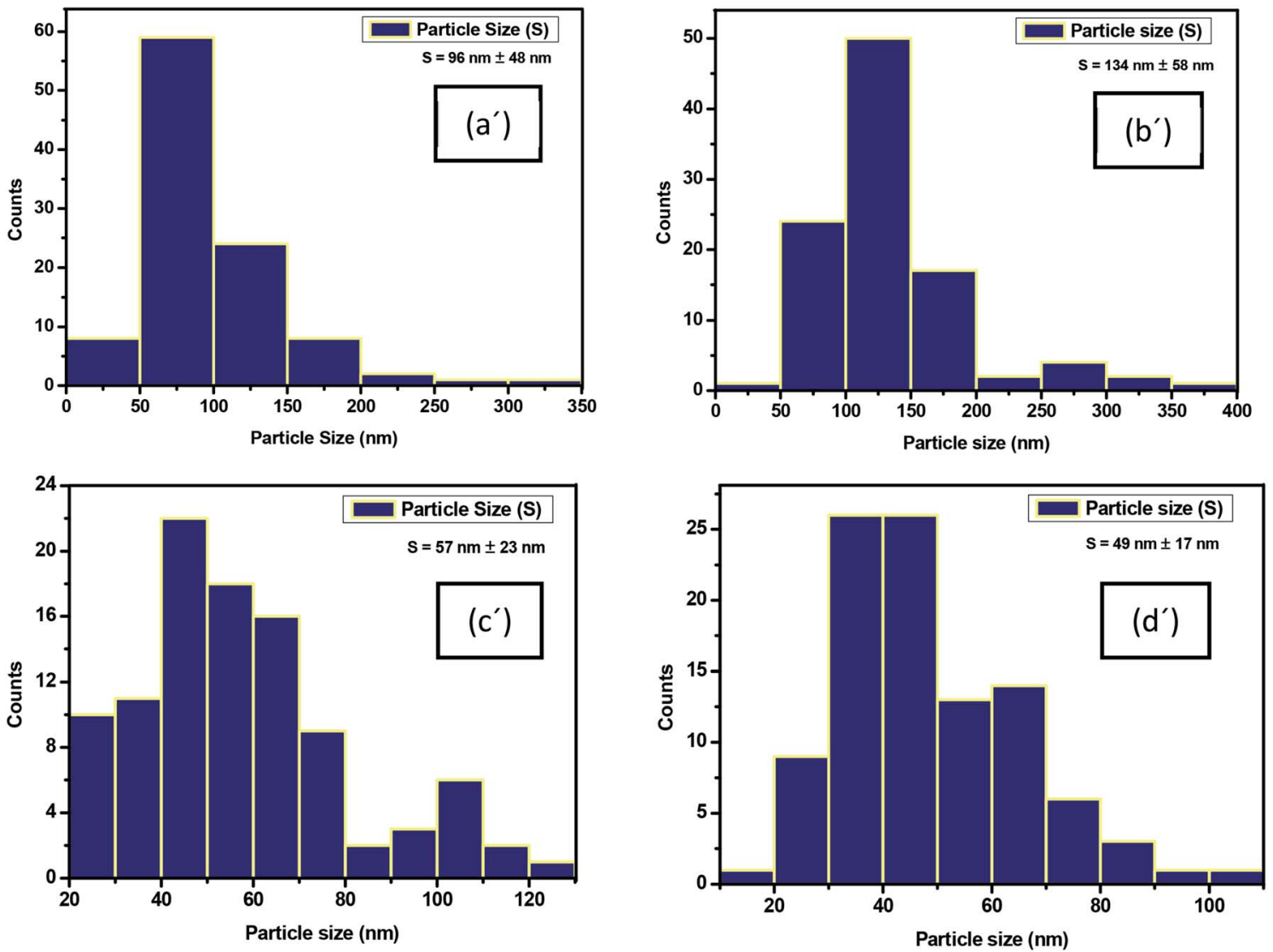

Fig. 7 Particle size distribution histogram of immobilized iron on (a') PET-Fe; (b') PET-NH $\mathrm{N}_{2}-\mathrm{Fe}$; $\left(c^{\prime}\right) \mathrm{PET}-\mathrm{Si}-\mathrm{NH} \mathrm{H}_{2}-\mathrm{Fe}$ and $\left(d^{\prime}\right) \mathrm{PET}-\mathrm{SH}-\mathrm{Fe}$. 
Results summarized in Table 2 shows that all of them were effective on immobilizing and stabilizing Fe-NPs on the polyester membrane at a considerable amount starting from 18.96 (wt\%) to 26.10 (wt\%). This suggests a predominantly physical and non-stoichiometric condensation of $\mathrm{Fe}$ nanoparticles through interaction with the organic entanglement. This can be explained by the interaction between the fibres : amine/thiol function groups as well as between amine/thiol : Fe. Combine effort of hydroxyl and thiol groups in 1-thioglycerol found to adhere the most effective interactions to immobilize and stabilize iron nanoparticles; can be due to the electrostatic interactions of $\mathrm{OH}$ groups and possible Lewis acid-base bond between thiol and ester derivatives reported by Joel Martínez et al. (2013).40,45 The highest $26.10 \%$ loading of Fe-NPs was observed in PET-SH-Fe followed by PET-Si-NH ${ }_{2}-\mathrm{Fe}(24.12 \%)$, PET-NH $\mathrm{N}_{2}-\mathrm{Fe}(19.02 \%)$ and PET-Fe (18.94\%) which added support to the claim of the effectiveness of 1-thioglycerol over PAMAM and APTES towards stabilization of Fe-NPs on polyester surface.

In our previous study, ${ }^{\mathbf{4 0}}$ we discussed the well-defined X-ray diffraction analysis of Fe-NPs immobilized polyester membranes prepared by the same approaches. Results showed an apparent peak at the $2 \theta$ of $44.90^{\circ}$ and $36.8^{\circ}$ corresponds to both zero-valent iron and iron oxide, which can be due to the rapid oxidation of the surface of the zerovalent iron and form a thin oxide layer as reported by Yi Mu et al. (2017) ${ }^{46}$ Earlier Mauricio A. V. Ramos et al. (2009) ${ }^{47}$ reported that the component proportion of oxide shell to the iron metal core of zerovalent iron nanoparticles can play a vital role in various contaminant removal processes where adsorption of inorganic/ organic species by zerovalent iron nanoparticles can be predominantly mediated by the oxide shells.

Possible changes in thermal properties due to the immobilization of iron was studied by thermogravimetric (TG) and differential scanning calorimetry (DSC) analysis. TGA analysis (see Fig. S4 of ESI $\dagger$ ) revealed a two common mass loss region at 80-100 ${ }^{\circ} \mathrm{C}$ and between $260-500{ }^{\circ} \mathrm{C}$ is the $T_{\mathrm{g}}$ and $T_{\mathrm{m}}$ of PET respectively. ${ }^{48} \mathrm{~A}$ slight shift in mass loss region of the ironloaded polyester membrane has been noticed can be due to the increases in the stability of polyester membrane due to the presence of iron particles. In DSC analysis (see Fig. 8), high intensity of heat flow as a result of the increase in heat conduction due to the presence of Fe-NPs was observed in all iron-immobilized polyester membrane over untreated membrane; provide evidence of thermal property improvement of functionalized nonwovens.

Table 2 Summary of particle size and wt\% of Fe-NPs immobilized on the polyester membrane

\begin{tabular}{|c|c|c|}
\hline Sample & $\begin{array}{l}\text { The particle size } \\
\text { of Fe-NPs (nm) }\end{array}$ & $\begin{array}{l}\mathrm{mg} \% \text { of } \\
\text { Fe-NPs immobilized }\end{array}$ \\
\hline PET-Fe & $96 \pm 48$ & 18.94 \\
\hline PET-NH ${ }_{2}-\mathrm{Fe}$ & $134 \pm 58$ & 19.02 \\
\hline $\mathrm{PET}-\mathrm{Si}-\mathrm{NH}_{2}-\mathrm{Fe}$ & $57 \pm 23$ & 24.12 \\
\hline PET-SH-Fe & $49 \pm 17$ & 26.10 \\
\hline
\end{tabular}

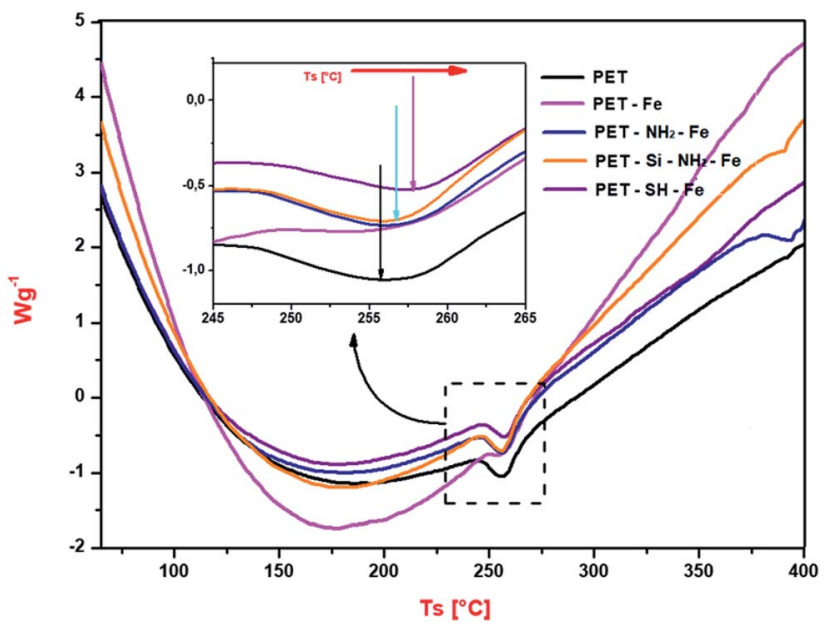

Fig. 8 DSC analysis of iron-immobilized polyester membranes.

\subsection{Part 2: analysis of heterogeneous Fenton-like removal of crystal violet dye.}

Crystal violet dye and pathogenic bacteria strain (S. Epidermidis and $E$. coli) were studied and analyzed for oxidative heterogeneous Fenton-like removal of toxic water pollutants. Crystal violet is a triphenylmethane dye regarded as a biohazard substance as it is poisonous and carcinogenic. ${ }^{\mathbf{4 9 , 5 0}}$ Crystal violet dye is being extensively used in textiles, medicine as well as in paints and printing ink. Staphylococcus epidermidis and Escherichia coli a severe concern for many communities are intimidating pathogenic infections. $S$. epidermidis is an etiological infection agent, which in contact causes substantial heights of mortality. On the other hand, E. coli is also one of the most common nosocomial pathogens can cause several disorders. It has been reported by several researchers that, these pollutants can persist in the environment over a significant amount of time releasing toxic effects in the environment, needs immediate attention..$^{51,52}$

3.2.1. Removal of dye as a function of time. Fenton-like removal of crystal violet dye as a function of time was studied by UV-vis spectrophotometer and plotted as shown in Fig. 9. The removal reactions of crystal violet dye using different membranes (PET-Fe, PET- $\mathrm{NH}_{2}-\mathrm{Fe}, \mathrm{PET}-\mathrm{Si}-\mathrm{NH}_{2}-\mathrm{Fe}$, and PET$\mathrm{SH}-\mathrm{Fe}$ ) were carried out under the same conditions (method explained in Section 2.5). The Fenton-like reaction involves the combined use of ferrous ions $\left(\mathrm{Fe}^{2+}\right)$ and hydrogen peroxide $\left(\mathrm{H}_{2} \mathrm{O}_{2}\right)$ to produce highly oxidation potential active oxygen species (such as hydroxyl free radicals) capable of degrading crystal violet dye. The characteristic absorption peak observed at $\lambda_{590 \mathrm{~nm}}$ attributed to the intensity of crystal violet. ${ }^{53}$

As shown in Fig. 9a-d, the intensity of the absorbance at $\lambda_{590}$ $\mathrm{nm}$ rapidly decreased, while exposed to an iron-immobilized polyester membrane (that ultimately provides $\mathrm{Fe}^{2+}$ ) and hydrogen peroxide, suggesting rapid generation of hydroxyl free radical that oxidized crystal violet dye into colourless degraded intermediates. All samples found to be effective towards the removal of crystal violet dye in a heterogeneous Fenton-like environment providing complete degradation by $22-68 \mathrm{~min}$. A 

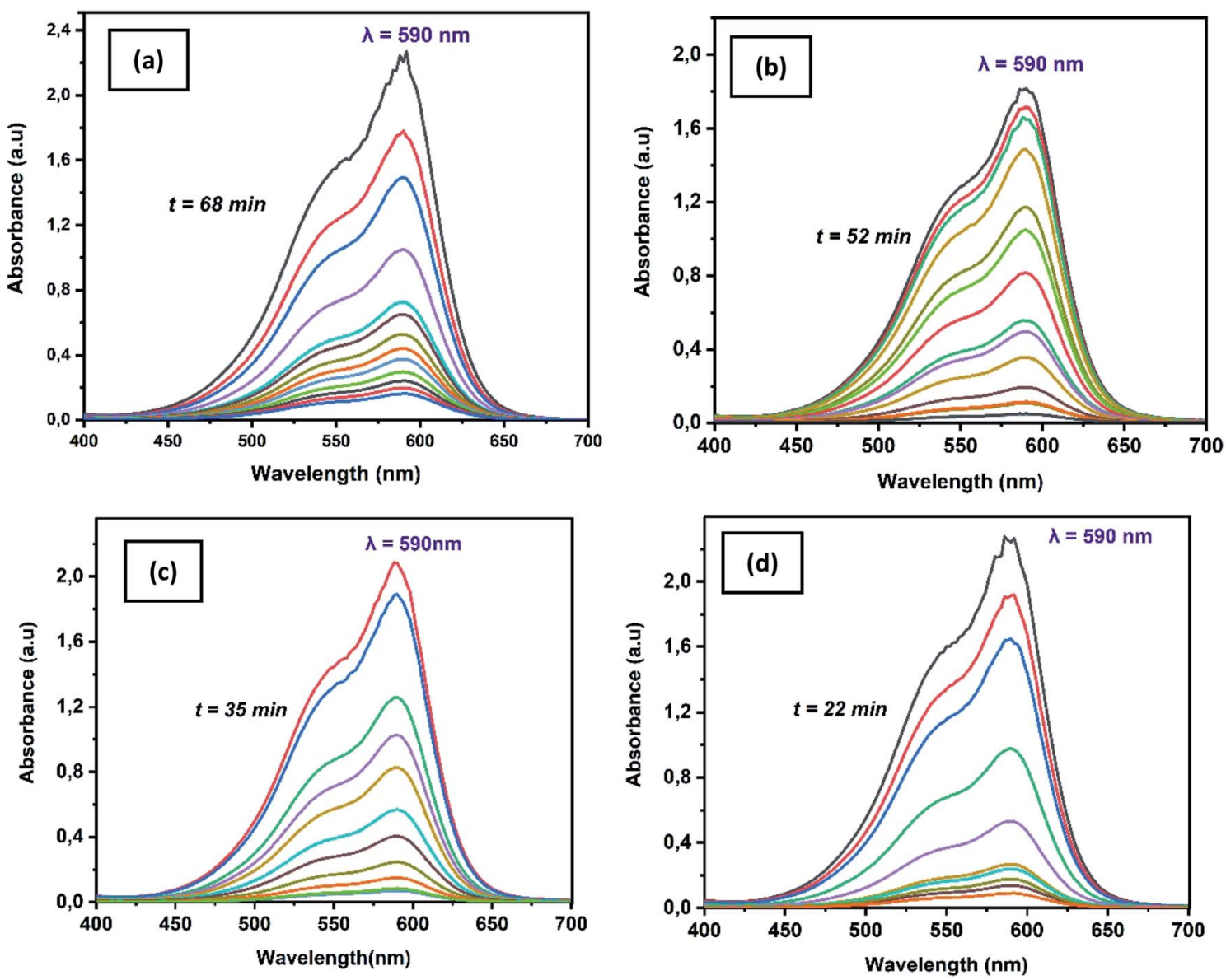

Fig. 9 UV-visible spectroscopy of heterogeneous Fenton-like removal of crystal violet dye using iron-immobilized fibrous membrane; (a) PET$\mathrm{Fe} / \mathrm{H}_{2} \mathrm{O}_{2}$, (b) $\mathrm{PET}-\mathrm{NH}_{2}-\mathrm{Fe} / \mathrm{H}_{2} \mathrm{O}_{2}$, (c) $\mathrm{PET}-\mathrm{Si}-\mathrm{NH}_{2}-\mathrm{Fe} / \mathrm{H}_{2} \mathrm{O}_{2}$, and (d) $\mathrm{PET}-\mathrm{SH}-\mathrm{Fe} / \mathrm{H}_{2} \mathrm{O}_{2}$ [Conditions: crystal violet dye $=3 \mathrm{~mL}$ (50 $\mathrm{mg} \mathrm{L}{ }^{-1}$ ), ironimmobilized fibrous membrane $=1 \mathrm{~cm}^{2}, \mathrm{H}_{2} \mathrm{O}_{2}=500 \mu \mathrm{L}(0.3 \mathrm{M}), \mathrm{pH}=5, T=25^{\circ} \mathrm{C}$.

close look at the colour removal performance of the individual sample shows that significantly fast removal $(98.87 \%$ in $22 \mathrm{~min})$ performance was achieved by PET-SH-Fe compare to other samples $(98.56 \%$ in $35 \mathrm{~min}, 98.35 \%$ in $52 \mathrm{~min}, 94.77 \%$ in 68 min for PET-Si- $\mathrm{NH}_{2}-\mathrm{Fe}$, PET- $\mathrm{NH}_{2}-\mathrm{Fe}$ and PET-SH-Fe, respectively). Fast removal of might be attributed to the stability, disparity and quantity of iron nanoparticles that strongly immobilized on the polyester surface, ensuring the maximum exposure of reagent, vigorous presence of ferrous ions $\left(\mathrm{Fe}^{2+}\right)$ thus the efficiency of producing striking hydroxyl free radicals for oxidation of dye.

3.2.1.1. Kinetics of colour removal of crystal violet dye. Degradation kinetics is one of the most important characteristics that represent the catalytic efficiency of the membrane and, therefore, largely illustrate the potential applications of the membrane. ${ }^{54}$ Herein, the kinetic experiments of heterogeneous Fenton-like removal of crystal violet dye with the use of ironimmobilized polyester nonwoven in presence of hydrogen peroxide were conducted by investigating the degradation rate versus the degradation time the results are shown in Table 3. The [instant/initial] absorbance ratio of the crystal violet band at $\lambda_{590 \mathrm{~nm}}\left(A_{t} / A_{0}\right)$, which accounts for the corresponding concentration ratio $\left(C_{t} / \mathrm{S}_{0}\right)$, allows plotting of $\ln \left(C_{t} / C_{0}\right)$ as a function of time according to eqn (3) as shown in Fig. 10a and b. The removal performance of the membranes has been presented in Fig. 10c.

$$
\ln \frac{C_{t}}{C_{0}}=\ln \frac{A_{t}}{A_{0}}-k t
$$

Model validation of reaction kinetics for crystal violet dye removal using iron-immobilized fibrous membrane is obtained by linear evolution in time of $\ln \left(C_{t} / C_{0}\right)$, as supported by $R^{2}$ values 95.84, 89.77, 95.34, 95.36 for PET-Fe $/ \mathrm{H}_{2} \mathrm{O}_{2}, \mathrm{PET}-\mathrm{NH}_{2}-\mathrm{Fe} /$ $\mathrm{H}_{2} \mathrm{O}_{2}$, PET-Si- $\mathrm{NH}_{2}-\mathrm{Fe} / \mathrm{H}_{2} \mathrm{O}_{2}$, and PET-SH-Fe $/ \mathrm{H}_{2} \mathrm{O}_{2}$ respectively. Plots summarized in Table 3 shows that all membranes exhibited good linear relationships of $\ln \left(C_{t} / C_{0}\right)$ versus reaction time following pseudo-second-order, pseudo-first-order, and first-order reaction kinetics with respect to complete removal of crystal violet dye. It is evident that among all membranes the rate constant and removal performance of PET-SH-Fe $/ \mathrm{H}_{2} \mathrm{O}_{2}$ is the highest $\left(0.1922 \mathrm{~min}^{-1}, 98.87 \%\right)$. Thus, it is of great interest that our result demonstrates fast and complete removal of dye as supported previously.

3.2.1.2. The postulated mechanism of dye removal. Characteristics property of zerovalent iron (immobilized in the 
Table 3 Pseudo-second-order, pseudo-first-order, and first-order reaction kinetics studies for heterogeneous Fenton-like removal of crystal violet dye

\begin{tabular}{|c|c|c|c|c|c|}
\hline Sample & Pollutant conc. $\left(\mathrm{mg} \mathrm{L}^{-1}\right)$ & ${ }^{a}$ Time (min) & ${ }^{b} k\left(\min ^{-1}\right)$ & ${ }^{c}\left(R^{2}\right)$ & Removal\% \\
\hline $\mathrm{PET}-\mathrm{Fe} / \mathrm{H}_{2} \mathrm{O}_{2}$ & 50 & 68 & 0.0494 & 95.84 & 94.77 \\
\hline PET- $\mathrm{NH}_{2}-\mathrm{Fe} / \mathrm{H}_{2} \mathrm{O}_{2}$ & 50 & 52 & 0.0789 & 89.77 & 98.35 \\
\hline $\mathrm{PET}-\mathrm{SH}-\mathrm{Fe} / \mathrm{H}_{2} \mathrm{O}_{2}$ & 50 & 22 & 0.1922 & 95.36 & 98.87 \\
\hline
\end{tabular}

${ }^{a}$ Reaction time required for complete colour removal. ${ }^{b} k$ : rate constant for the 1 st order kinetics, and is expressed in min ${ }^{-1}$. ${ }^{c} R^{2}$ : correlation coefficient of the linear regression.

polyester membrane) to produce iron ions followed by participation in Fenton-like reaction in presence of hydrogen peroxide generates high oxidation potential of hydroxyl free radical (The hydroxyl radical $(\cdot \mathrm{OH})$ has a standard oxidation-reduction potential of $2.8 \mathrm{~V}$ ) (see Fig. 11 and reaction (4)-(7)). Based on the mechanism of Fenton-like reaction and previous reports ${ }^{\mathbf{4 3 , 5 5 , 5 6}}$ an initial mineralization pathway has also been proposed (see Fig. 12). It can see that there are number conduits for mineralization of crystal violet dye as a function of interaction with oxidizing species such as hydroxyl free radicals, generated through Fenton reaction.

The removal of crystal violet dye was attributed to the synergistic effect caused by free radicals and other reactive species on the central carbon portion of crystal violet dye structure (see Fig. 12A). ${ }^{39}$ As found in the results (discussed in Section 3.2.1) upon oxidation, the dye becomes colourless, indicating the removal of the color bearing group and possible conversion into degraded intermediates. In the initial
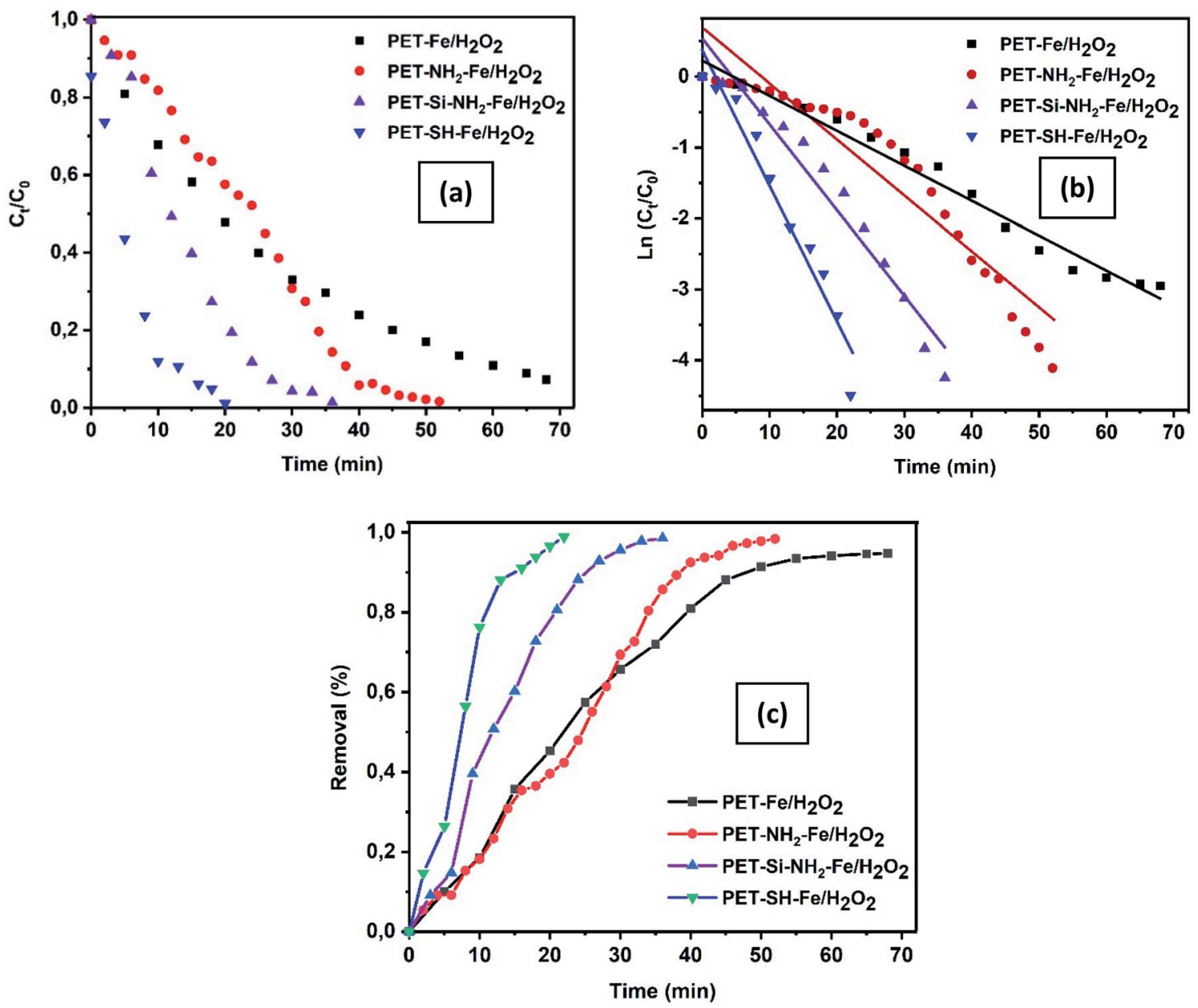

Fig. 10 Evolution of (a) $C_{t} / C_{0}$, (b) $\ln \left(C_{t} / C_{0}\right)$ and (c) the removal yield in respect to time [Conditions: crystal violet dye $=3 \mathrm{~mL}\left(50 \mathrm{mg} \mathrm{L}^{-1}\right)$, ironimmobilized fibrous membrane $\left.=1 \mathrm{~cm}^{2}, \mathrm{H}_{2} \mathrm{O}_{2}=500 \mu \mathrm{L}(0.3 \mathrm{M}), \mathrm{pH}=5, T=25^{\circ} \mathrm{C}\right]$. 


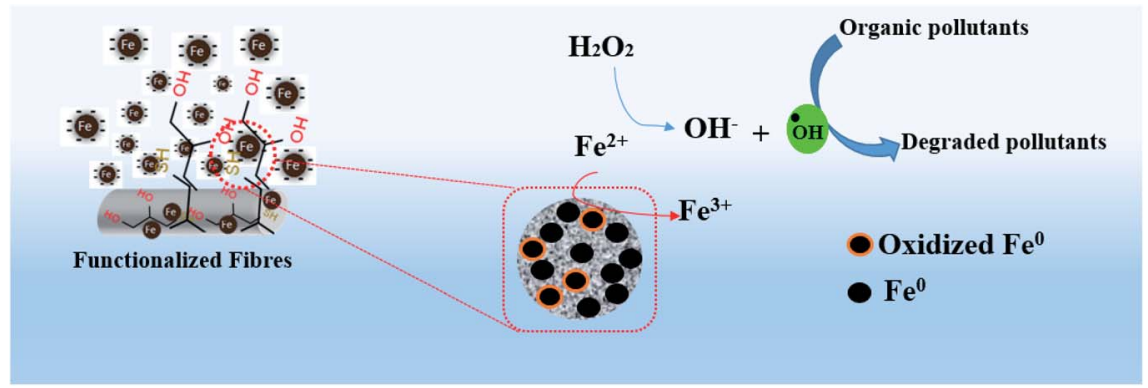

Fig. 11 Schematic postulated mechanism of removal of crystal violet dye as a potential organic pollutant.

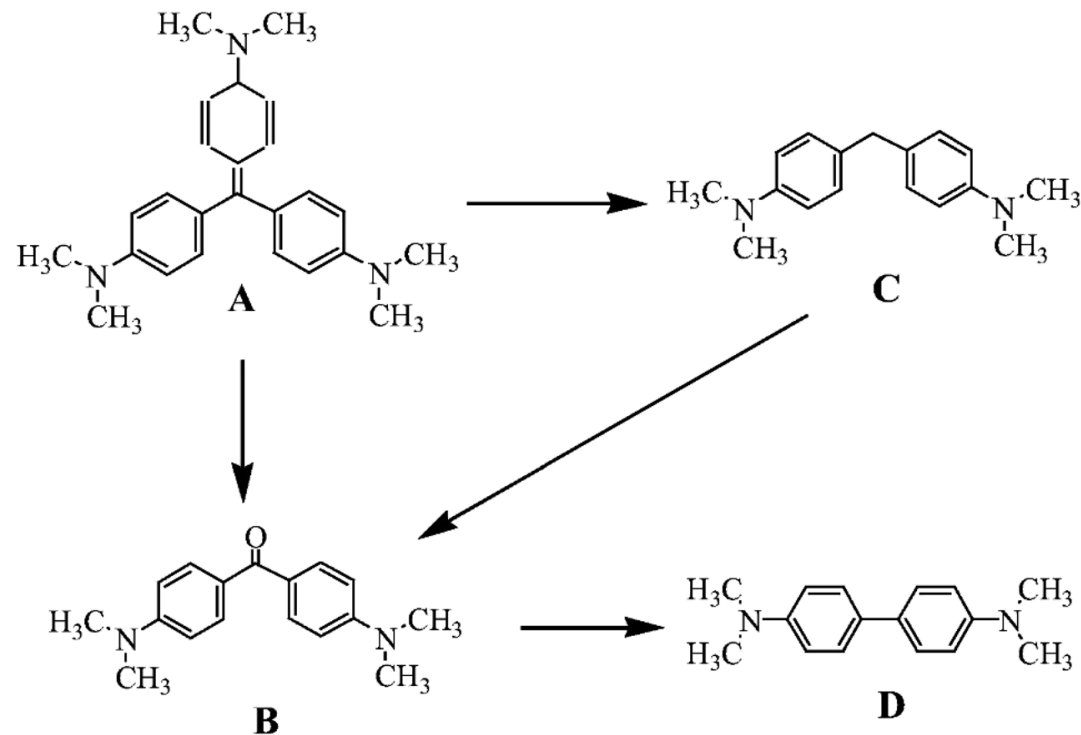

Fig. 12 Initial mineralization pathway of crystal violet dye. (A) Crystal violet; (B) 4-(N,N-dimethylamino)-40-(NO,N'-dimethylamino)benzophenone; (C) 4-(N,N-dimethylamino)-40-(NO,N'-dimethylamino)diphenylmethane; (D) 4-(N,N-dimethylamino)-40-(NO,N'-dimethylamino) dimethylaniline.

assumption, R. E. Palma-Goyes et al. $(2010)^{56}$ and F. GuzmanDuque et al. (2011) ${ }^{57}$ suggested that due to oxidation crystal violet may degrade into 4 -( $N, N$-dimethylamino $)-4^{\prime}$ - $\left(N^{\prime}, N^{\prime}\right.$-dimethylamino) benzophenone (see Fig. 12B) or 4 - $(N, N$-dimethylamino)- $4^{\prime}$-( $N^{\prime}, N^{\prime}$-dimethylamino) diphenylmethane (see Fig. 12C).

However, a secondary degradation of these degraded intermediates occurs due to constant interaction with hydroxyl free radicals in the reaction bath and further degradation into 4( $N, N$-dimethylamino)- $4^{\prime}$-( $N^{\prime}, N^{\prime}$-dimethylamino) dimethylaniline (see Fig. 12D). ${ }^{55}$ Finally, the gradual cleavage of the aromatic degraded intermediates would lead to mineralize into carboxylic acids prior to dissociate into $\mathrm{H}_{2} \mathrm{O}$ and $\mathrm{CO}_{2}$ as illustrated in reaction (8) and (9).

The postulates reaction mechanism involves three steps as follows;

(i) The process of producing iron ions and reactive species

$$
\begin{gathered}
\mathrm{Fe}^{0}+2 \mathrm{H}^{+} \rightarrow \mathrm{Fe}^{2+}+\mathrm{H}_{2} \\
\mathrm{Fe}^{0}+2 \mathrm{Fe}^{3+} \rightarrow 3 \mathrm{Fe}^{2+}
\end{gathered}
$$

$$
\begin{aligned}
& \mathrm{Fe}^{0}+\mathrm{H}_{2} \mathrm{O}_{2}+2 \mathrm{H}^{+} \rightarrow \mathrm{Fe}^{2+}+2 \mathrm{H}_{2} \mathrm{O} \\
& \mathrm{Fe}^{2+}+\mathrm{H}_{2} \mathrm{O}_{2} \rightarrow \mathrm{Fe}^{3+}+\mathrm{HO}^{-}+\cdot \mathrm{OH}
\end{aligned}
$$

(ii) The process of colour removal

$$
\text { Crystal violet }+\cdot \mathrm{OH} \rightarrow \text { degraded intermediates }
$$

(iii) The process of mineralization

$$
\text { Degraded intermediates }+\cdot \mathrm{OH} \rightarrow \mathrm{CO}_{2}+\mathrm{H}_{2} \mathrm{O}
$$

3.2.1.3. Analysis of toxicity reduction. Toxicity reduction is an important parameter in any pollutant removal process. Reduction of chemical oxygen demand (COD) due to the heterogeneous Fenton-like removal of crystal violet dye from water has been systematically investigated according to the method explained in Section 2.5.4. Fig. 13 showed the evolution of COD concentration after removal of crystal violet dye using various membranes ((a) PET-Fe $/ \mathrm{H}_{2} \mathrm{O}_{2}$; (b) PET- $\mathrm{NH}_{2}-\mathrm{Fe} / \mathrm{H}_{2} \mathrm{O}_{2}$; (c) PET- 


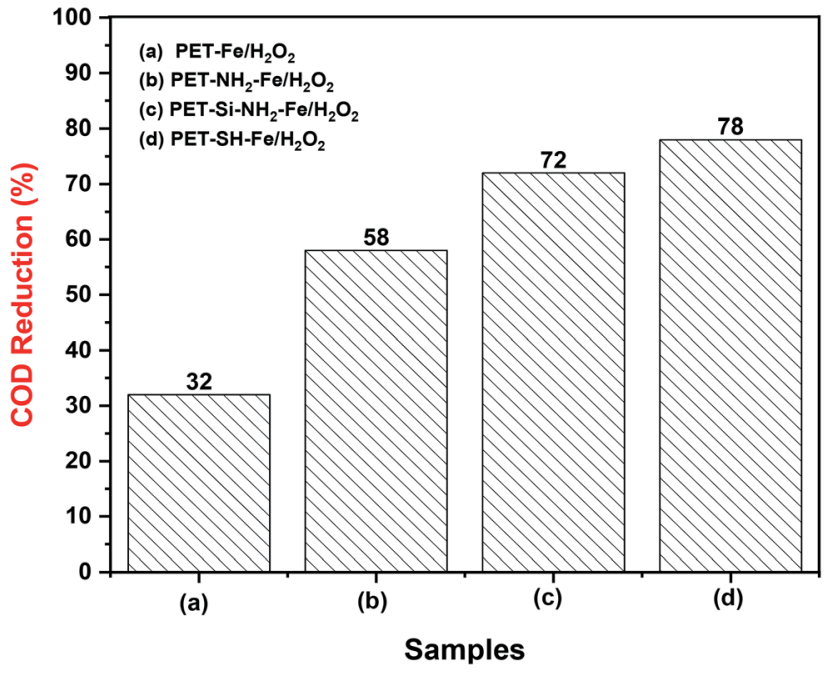

Fig. 13 Toxicity reduction analysis (a) $\mathrm{PET}-\mathrm{Fe} / \mathrm{H}_{2} \mathrm{O}_{2}$; (b) $\mathrm{PET}-\mathrm{NH}_{2}-$ $\mathrm{Fe} / \mathrm{H}_{2} \mathrm{O}_{2}$; (c) $\mathrm{PET}-\mathrm{Si}-\mathrm{NH}_{2}-\mathrm{Fe} / \mathrm{H}_{2} \mathrm{O}_{2}$; (d) $\mathrm{PET}-\mathrm{SH}-\mathrm{Fe} / \mathrm{H}_{2} \mathrm{O}_{2}$ [Conditions: crystal violet dye $=3 \mathrm{~mL}\left(50 \mathrm{mg} \mathrm{L}^{-1}\right)$, iron-immobilized fibrous membrane $\left.=1 \mathrm{~cm}^{2}, \mathrm{pH}=5, T=25^{\circ} \mathrm{C}\right]$.
$\mathrm{Si}-\mathrm{NH}_{2}-\mathrm{Fe} / \mathrm{H}_{2} \mathrm{O}_{2}$; (d) PET-SH-Fe $/ \mathrm{H}_{2} \mathrm{O}_{2}$ ). The samples were analyzed for COD reduction immediately after complete decolouration. Results indicates a considerable reduction (78\%) of COD by PET-SH-Fe $/ \mathrm{H}_{2} \mathrm{O}_{2}$ treatment followed by PET-Si- $\mathrm{NH}_{2}-$ $\mathrm{Fe} / \mathrm{H}_{2} \mathrm{O}_{2}$ (72\%), PET- $\mathrm{NH}_{2}-\mathrm{Fe} / \mathrm{H}_{2} \mathrm{O}_{2}(58 \%)$ and PET-Fe $/ \mathrm{H}_{2} \mathrm{O}_{2}$ (32\%). Reduction of COD attributed to the removal of dye molecules and their intermediates.

However, the incomplete reduction of COD of all samples after complete colour removal can be due to the remaining degraded intermediates (discussed in Section 3.2.1.2). From the results, it was further concluded that iron immobilized on polyester nonwoven membrane mediated by thiol groups adhere to the superior catalytic property by mineralizing maximum degraded intermediates of crystal violet into nontoxic elements can be due to the stabilization, uniform dispersion and strong binding of Fe-NPs as supported by SEM, TGA and DSC analysis. Nevertheless, in all samples a longer reaction between degraded intermediates and radicals may enhance the COD reduction performance as suggested by J. Liu et al. (2019), ${ }^{58}$ hence a longer treatment after colour removal is recommended for complete toxicity reduction through the designed treatment process.
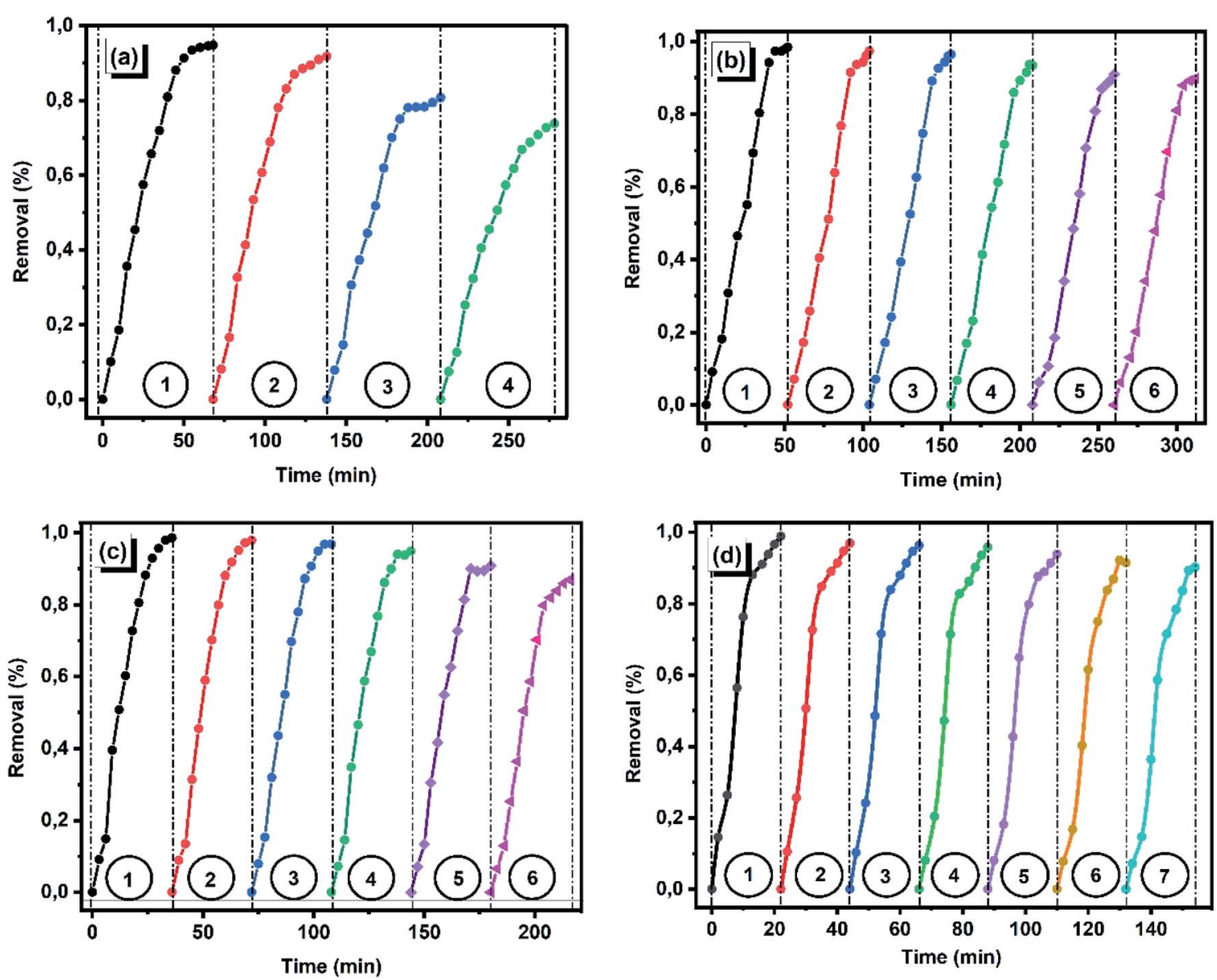

Fig. 14 Recyclability and repeatability analysis of iron-immobilized fibrous membrane; (a) $\mathrm{PET}-\mathrm{Fe} / \mathrm{H}_{2} \mathrm{O}_{2}$, (b) $\mathrm{PET}-\mathrm{NH} \mathrm{H}_{2}-\mathrm{Fe} / \mathrm{H}_{2} \mathrm{O}_{2}$, (c) $\mathrm{PET}-\mathrm{Si}-$ $\mathrm{NH}_{2}-\mathrm{Fe} / \mathrm{H}_{2} \mathrm{O}_{2}$, and (d) $\mathrm{PET}-\mathrm{SH}-\mathrm{Fe} / \mathrm{H}_{2} \mathrm{O}_{2}$ [Conditions: crystal violet dye $=3 \mathrm{~mL}\left(50 \mathrm{mg} \mathrm{L}^{-1}\right)$, iron-immobilized fibrous membrane $=1 \mathrm{~cm}^{2}, \mathrm{H}_{2} \mathrm{O}_{2}$ $=500 \mu \mathrm{L}(0.3 \mathrm{M}), \mathrm{pH}=5, T=25^{\circ} \mathrm{C}$. 
Table 4 Comparison of the studies focused on the removal of crystal violet dye through different AOPs

\begin{tabular}{|c|c|c|c|c|c|c|}
\hline Sample & $\begin{array}{l}\text { Conc. of } \\
\text { pollutant }\end{array}$ & Time & $\begin{array}{l}\text { Rate constant, } \\
k\left(\min ^{-1}\right)\end{array}$ & $\begin{array}{l}\text { No. of } \\
\text { reusability cycles }\end{array}$ & $\begin{array}{l}\text { Toxicity reduction } \% \\
\text { (TOC/COD) }\end{array}$ & Reference \\
\hline MMT-Fe (Fenton) & $0.060 \mathrm{mM}$ & $120 \mathrm{~min}$ & 0.2220 & - & $41.5^{b}$ & 59 \\
\hline $\mathrm{GO} / \mathrm{PbBiO}_{2} \mathrm{Br}-\mathrm{UV}$ & $10 \mathrm{mg} \mathrm{L}^{-1}$ & $12 \mathrm{~h}$ & 0.1278 & 6 & - & 61 \\
\hline Fe loaded ZSM-5 zeolite (Fenton) & $3 \mathrm{mM}$ & $120 \mathrm{~min}$ & 0.1811 & 3 & $76^{a}$ & 62 \\
\hline $\mathrm{TiO}_{2} /$ clinoptilolites-UV & $12 \mathrm{mg} \mathrm{L}^{-1}$ & $100 \mathrm{~min}$ & 0.019 & 5 & - & 63 \\
\hline $\mathrm{PET}-\mathrm{NH}_{2}-\mathrm{Fe} / \mathrm{H}_{2} \mathrm{O}_{2}$ & $50 \mathrm{mg} \mathrm{L}^{-1}$ & $52 \mathrm{~min}$ & 0.0816 & 6 & $58^{a}$ & This work \\
\hline PET-Si-NH $\mathrm{H}_{2}-\mathrm{Fe} / \mathrm{H}_{2} \mathrm{O}_{2}$ & $50 \mathrm{mg} \mathrm{L}^{-1}$ & $36 \mathrm{~min}$ & 0.1187 & 6 & $72^{a}$ & This work \\
\hline $\mathrm{PET}-\mathrm{SH}-\mathrm{Fe} / \mathrm{H}_{2} \mathrm{O}_{2}$ & $50 \mathrm{mg} \mathrm{L}^{-1}$ & $22 \min$ & 0.1919 & 7 & $78^{a}$ & This work \\
\hline
\end{tabular}

${ }^{a}$ Toxicity reduction analyzed by chemical oxygen demand analysis. ${ }^{b}$ Toxicity reduction analyzed by total organic carbon analysis.

3.2.1.4. Analysis of reusability studies. One of the great advantages of fibrous heterogeneous catalysts is the possibility to be recovered/recycled and reused in consecutive degradation/ removal cycles. To study the durability and stability of the ironimmobilized polyester membrane catalysts, the catalyst was repeatedly used for removal of crystal violet dye in the same experimental condition (as per the method stated in Section 2.5). The results are reported in Fig. 14, indicating that all catalysts can be recovered and reused for four (PET-Fe), six (PET- $\mathrm{NH}_{2}-\mathrm{Fe}$ and PET-Si-NH $\mathrm{N}_{2}-\mathrm{Fe}$ ) and seven (PET-SH-Fe) consecutive cycles with or without a significant decline in removal performance. A substantial decline in removal performance after three/four repeated use for PET-Fe catalyst could be due to the loosely attached iron nanoparticles on the membrane, which may leach to the solution (causing secondary pollutants) during preceding removal reaction. On the other, iron immobilized on PAMAM, APTES and SH grafted samples shows more robust and stable characteristics of iron nanoparticles providing at least above $90 \%$ removal even after six reuse. This can be explained by the key role of amine/thiol functional groups that bind and shielded the zerovalent iron nanoparticles and prevent leaching, which results in high durability. Overall, the resultant catalyst exhibited excellent repetitive-use performance, which was of great interest as compared with recently introducing AOP systems reported in the literature as summarized in Table 4.

3.2.1.5. Role of amine/thiol and hydrophilic groups. Amine and thiol groups with terminal $\mathrm{NH}_{2}$ and $\mathrm{SH}$ groups grafted on polyester membranes demonstrated a key role in fixation and stabilization of zerovalent iron nanoparticles and adsorption of the pollutants over the surface of fibrous membranes. As observed in Table 2 (see Section 3.1.3), adequate loading of FeNPs was achieved by using PAMAM, APTES or thioglycerol in comparison with original polyester membranes. This may be ascribed to the gradual protonation of the amine group and thus improve the fixation of the nanoparticles followed by better catalytic performance. Here, amine ends of APTES and PAMAN immobilize and interact with the iron nanoparticle, involving an electrostatic interaction. However, in the case of thioglycerol, the terminal groups were hydroxyls $(\cdot \mathrm{OH})$ that exposed for attachment to the Fe-NPs surface. Herein, during the contact of thiol or amines with the iron particles, the weakest part of the bridge structure broke resulted in a rupture. The resulting rupture force can be explained the difference between thiol and amines. According to the SEM and catalytic activities, it was found that thiol grafting evidence high dispersion of Fe nanoparticles and the good removal of crystal violet dye. Consequently, the interaction force of thiol is stronger than those of amines, indicating the causes of most probable rupture with iron nanoparticles. This was in good agreement with previously published work. ${ }^{\mathbf{3 8 , 6 4 , 6 5}}$ On the other hand, strong interactions between thiol groups and Fe explain the lower particles size on PET-SH, in agreement with previous data. ${ }^{66}$ This was accompanied by the high density of Fe for PET-SH-Fe as compared to APTES and PAMAM grafted nonwoven, due to the high affinity of $\mathrm{S}$ atoms towards $\mathrm{Fe}$ nanoparticles. The evidence of the uniform and high density of iron nanoparticles is provided by SEM analysis (see Section 3.1.3 and Fig. S3 of ESI†).

Additionally, by analyzing the contact angle of each polyester membrane after iron incorporation results in increased hydrophilic character (see Fig. S5 of ESI $\dagger$ ), provides better stability of the materials, thus improved removal of crystal violet dye. The wettability of the fibres appeared to be developed uniformly for all connected fibre. This result has an interesting role for the continuous adsorption of crystal violet dye molecules, which further reveals the chemical moiety behind the high removal performance of as-prepared membranes.

3.2.1.6. Effect of $\mathrm{pH}$, iron concentration, and $\mathrm{H}_{2} \mathrm{O}_{2}$ concentration on colour removal. The initial $\mathrm{pH}$ of the adsorption medium, the concentration of dye and reagents is a very significant parameter affecting the adsorption process in heterogeneous catalysis system. ${ }^{67}$ The effect of $\mathrm{pH}$ on the oxidation of crystal violet dye showed an interesting trend on all samples due to stabilization and immobilization of solid zerovalent ion nanoparticles on amine/thiol grafted polyester membranes. The removal performance of the membranes as summarized in Fig. 15 reveals that even though homogeneous Fenton reaction best operates in $\mathrm{pH} 3-4$ (very acidic) whereas as prepared heterogeneous catalysts (PET-SH-Fe, $\mathrm{PET}-\mathrm{Si}-\mathrm{NH}_{2}-\mathrm{Fe}$, and PET- $\mathrm{NH}_{2}-\mathrm{Fe}$ ) gives best removal efficiency at $\mathrm{pH}-5$, which is 
(a)

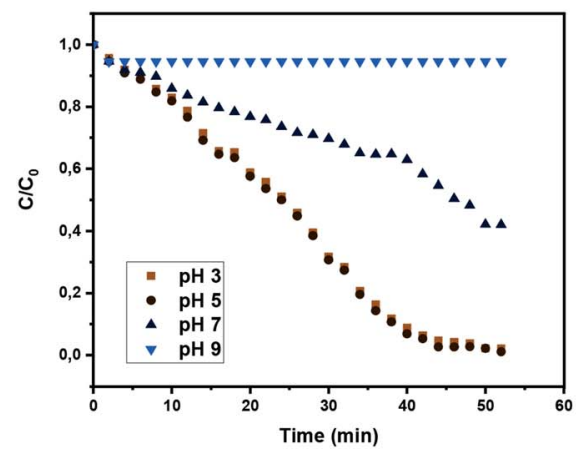

(b)

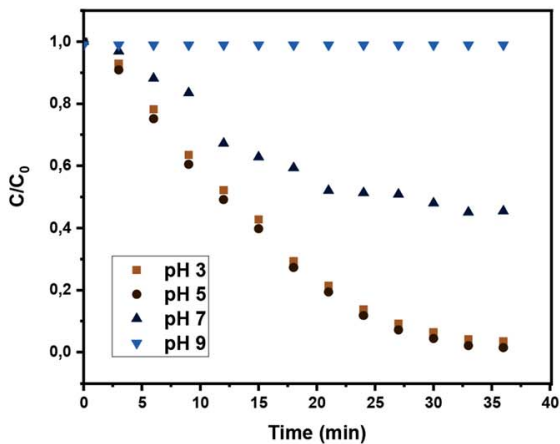

(c)

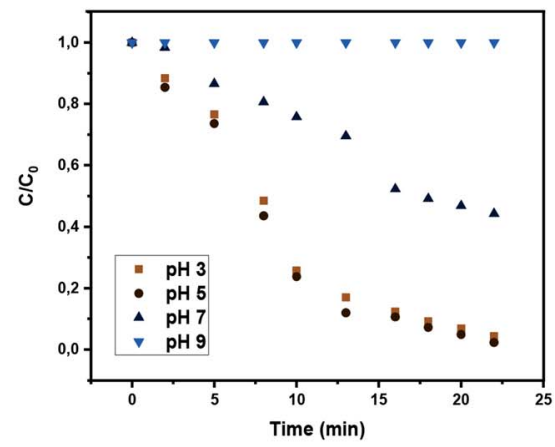

Fig. 15 Effect of different $\mathrm{pH}\left(3,5,7\right.$, and 9) on heterogeneous oxidative Fenton-like color removal; (a) $\mathrm{PET}-\mathrm{NH}_{2}-\mathrm{Fe} / \mathrm{H}_{2} \mathrm{O}_{2}$; (b) PET-Si-NH $2-\mathrm{Fe} /$ $\mathrm{H}_{2} \mathrm{O}_{2}$; (c) PET-SH-Fe/ $\mathrm{H}_{2} \mathrm{O}_{2}$ [Conditions: crystal violet dye $=3 \mathrm{~mL}\left(50 \mathrm{mg} \mathrm{L}^{-1}\right)$, iron-immobilized fibrous membrane $=1 \mathrm{~cm}^{2}, \mathrm{H}_{2} \mathrm{O}_{2}=500 \mu \mathrm{L}(0.3$ M), $\left.T=25^{\circ} \mathrm{C}\right]$.
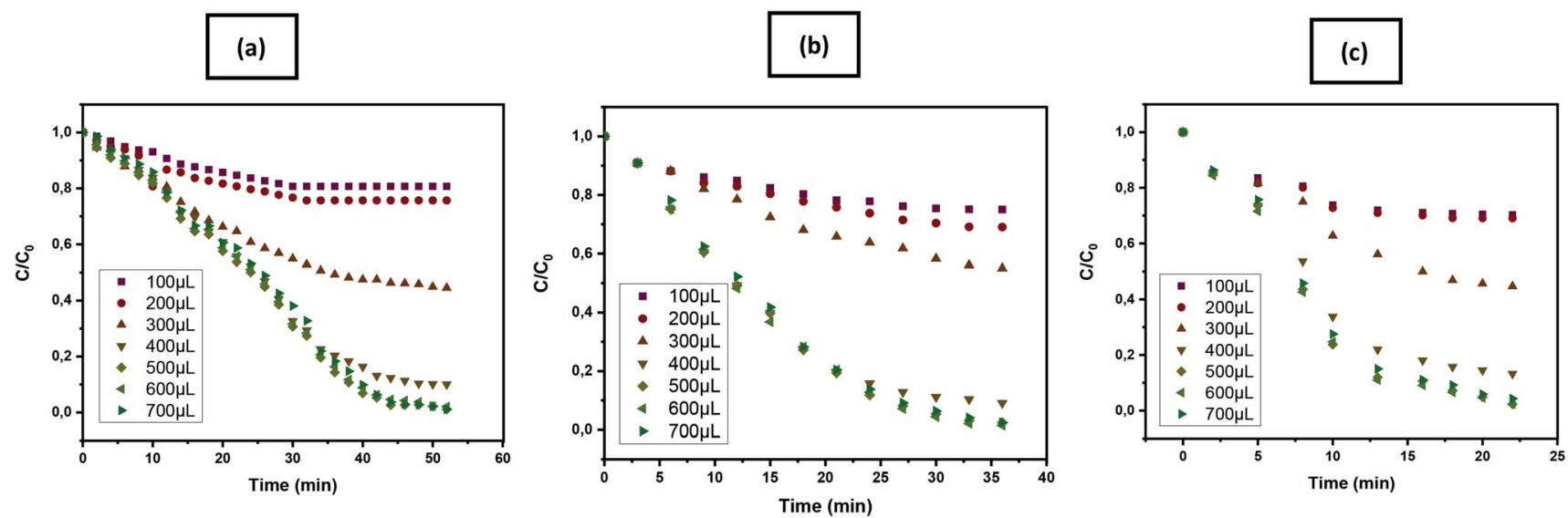

Fig. 16 Effect of hydrogen peroxide dossing $(100 \mu \mathrm{L}$ to $700 \mu \mathrm{L})$ on heterogeneous oxidative Fenton-like color removal; (a) $\mathrm{PET}-\mathrm{NH}_{2}-\mathrm{Fe} / \mathrm{H}_{2} \mathrm{O}_{2}$; (b) $\mathrm{PET}-\mathrm{Si}-\mathrm{NH}_{2}-\mathrm{Fe} / \mathrm{H}_{2} \mathrm{O}_{2}$; (c) $\mathrm{PET}-\mathrm{SH}-\mathrm{Fe} / \mathrm{H}_{2} \mathrm{O}_{2}$ [Conditions: crystal violet dye $=3 \mathrm{~mL}\left(50 \mathrm{mg} \cdot \mathrm{L}^{-1}\right)$, iron-immobilized fibrous membrane $=1 \mathrm{~cm}{ }^{2}$, $\mathrm{pH}=5, T=25^{\circ} \mathrm{C}$.

due to the characteristic advantage of the solid iron particles (zerovalent iron nanoparticles). ${ }^{40}$

This will considerably solve the unsatisfactory action (acidification to reach $\mathrm{pH} 3$ ) needed on the wastewater before or during Fenton like detoxification. However, in the case of basic $\mathrm{pH}$, the results showed very low catalytic activities, because of net negative surface charges on the catalyst surface cancelling the efficiency of reactive species responsible for the removal of crystal violet dye.

Measurement of the catalytic activities for different concentration of iron present in each catalysts [PET-SH-Fe $(26.10 \%)$, PET-Si- $\mathrm{NH}_{2}-\mathrm{Fe}(24.12 \%)$ and $\left.\mathrm{PET}-\mathrm{NH}_{2}-\mathrm{Fe}(19.02 \%)\right]$ as availed by TGA analysis (see Table 2 of Section 3.1.3) demonstrates appreciable changes in removal performance as a function of time as observed in Fig. 9. This phenomenon indicates that the number of iron nanoparticles present in the as fibrous membrane can influence the oxidative removal of pollutants.

As of characteristics behaviour of Fenton reaction, the reaction performance and production of reactive species greatly influenced by the quantity and ratio of the reagents used. The effect of different extent of hydrogen peroxide on removal performance has been studied for all samples. A range of capacity starting from 100 to $700 \mu \mathrm{L}(0.3 \mathrm{M})$ was studied. The evaluation of colour removal in terms $C_{t} / C_{0}$ as shown in Fig. 16 shows that $\mathrm{H}_{2} \mathrm{O}_{2}$ concentration bellow $300 \mu \mathrm{L}$ showed poor or insufficient dye removal. This is because the low concentration of $\mathrm{H}_{2} \mathrm{O}_{2}$ is too concentrated to react with the mineralized iron to form sufficient hydroxyl radicals to fully oxidize crystal violet. However, $400 \mu \mathrm{L}$ to $500 \mu \mathrm{L}$ showed complete removal of dye in similar experimental condition although the efficiency of the reaction was also quite different. When the concentration of $\mathrm{H}_{2} \mathrm{O}_{2}$ was gradually increased, the final removal rate reached nearly $97 \%$ to $99 \% .500 \mu \mathrm{L} \mathrm{H}_{2} \mathrm{O}_{2}$ on the reactor provides the fastest removal is also the point where the reaction is saturated. After the saturation point, the reaction efficiency even if for a high amount of $\mathrm{H}_{2} \mathrm{O}_{2}$ is negative. This phenomenon indicates that high and imbalance ratio of reagents cannot increase the degradation rate as linear regression rather showed no improvement after saturation. 

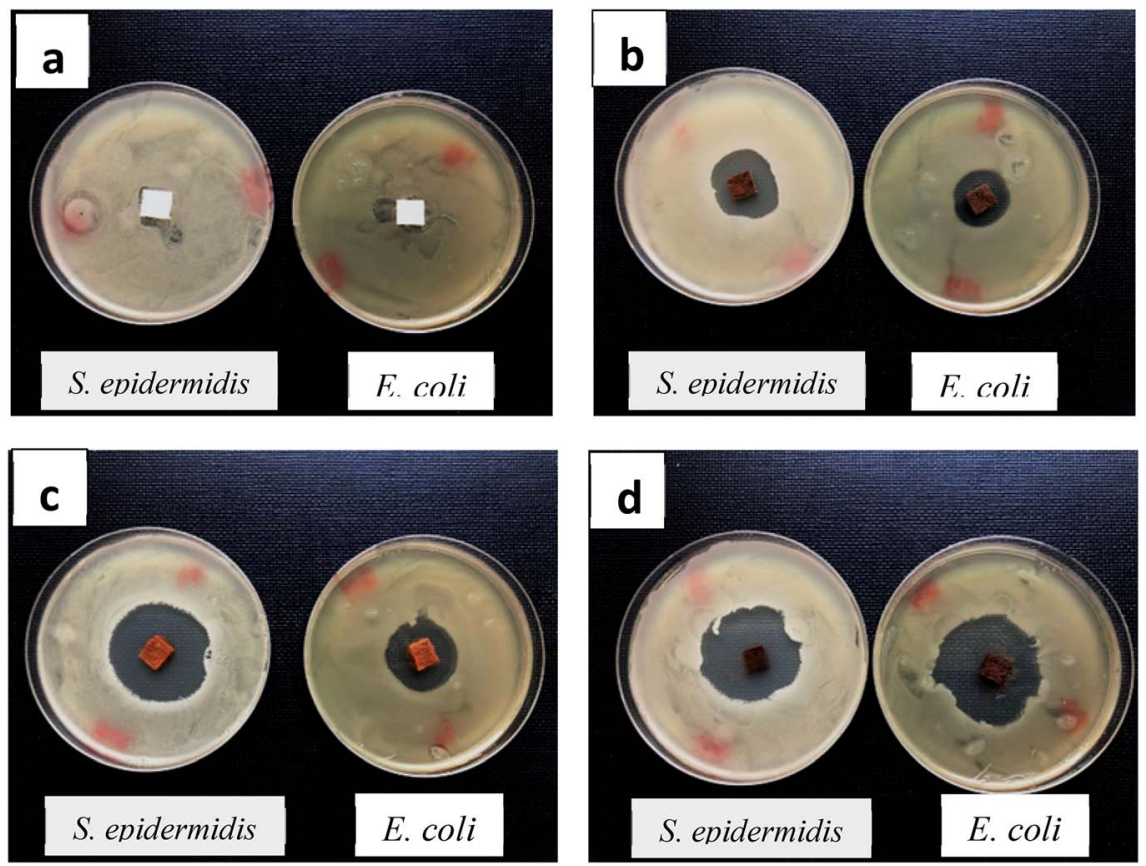

Fig. 17 Diffusivity and zone inhibitory test of differently iron-immobilized fibrous membranes; (a) untreated PET, (b) PET - PET-Si-NH ${ }_{2}-\mathrm{Fe}$ (c) $\mathrm{PET}-\mathrm{NH}_{2}-\mathrm{Fe}$ and (d) PET-SH-Fe.

3.2.2. Analysis of antibacterial activities. The catalytic behaviour of the membranes (PET-Si-NH $\mathrm{NH}_{2}-\mathrm{Fe}, \mathrm{PET}-\mathrm{SH}-\mathrm{Fe}$, and PET- $\mathrm{NH}_{2}-\mathrm{Fe}$ ) was studied under natural conditions through diffusivity and zone inhibitory analysis against both Grampositive and Gram-negative bacteria (S. epidermidis and E. coli) strains as per the method described in Section 2.6. A blank experiment was conducted using an untreated polyester membrane showed no inhibition zone, which means the polyester membrane does not possess antibacterial behaviour if not treated with additional antibacterial agents. However, upon immobilizing iron nanoparticles, polyester membranes effectively inhibited the bacterial growth starting showing the inhibition zone diameter from $21 \mathrm{~mm}$ to $38 \mathrm{~mm}$ (see Fig. 17) (According to ISO 20645 standard, the outspreading up to $1 \mathrm{~mm}$ inhibition zone and no growth under specimen or no inhibition zone is accepted as effective). ${ }^{68,69}$

This result is of great importance and can be explained by the strong capacity of the iron nanoparticle immobilized on polyester membrane to alter the membrane of $E$. coli and $S$.

Table 5 The zone of inhibition ${ }^{a}(\mathrm{~mm})$ analysis of membranes according to test method ISO 20645

\begin{tabular}{|c|c|c|}
\hline Sample & $\begin{array}{l}\text { Staphylococcus } \\
\text { epidermidis }\end{array}$ & $\begin{array}{l}\text { Escherichia } \\
\text { coli }\end{array}$ \\
\hline PET & - & - \\
\hline PET - PET-Si-NH ${ }_{2}-\mathrm{Fe}$ & $26 \mathrm{~mm}$ & $21 \mathrm{~mm}$ \\
\hline $\mathrm{PET}-\mathrm{NH}_{2}-\mathrm{Fe}$ & $35 \mathrm{~mm}$ & $26 \mathrm{~mm}$ \\
\hline PET-SH-Fe & $35 \mathrm{~mm}$ & $38 \mathrm{~mm}$ \\
\hline
\end{tabular}

${ }^{a}$ Mean values were given in the table after performing three tests of each analysis. epidermidis, inducing cell wall rupture. This synergistic antibacterial effect iron nanoparticle is consistent with the mechanism explained elsewhere. ${ }^{\mathbf{1 8 , 7 0 , 7 1}}$ The zone inhibition diameter (see Table 5) reveals that the PET-SH-Fe and PET- $\mathrm{NH}_{2}-\mathrm{Fe}$ membranes were more robust compared to $\mathrm{PET}-\mathrm{Si}-\mathrm{NH}_{2}-\mathrm{Fe}$. This can be due to the presence of a considerable amount of stability, the mass of iron nanoparticles, finer particles size and with high surface area ${ }^{72}$ and antibacterial behaviour of PAMAM dendrimer. $^{18}$

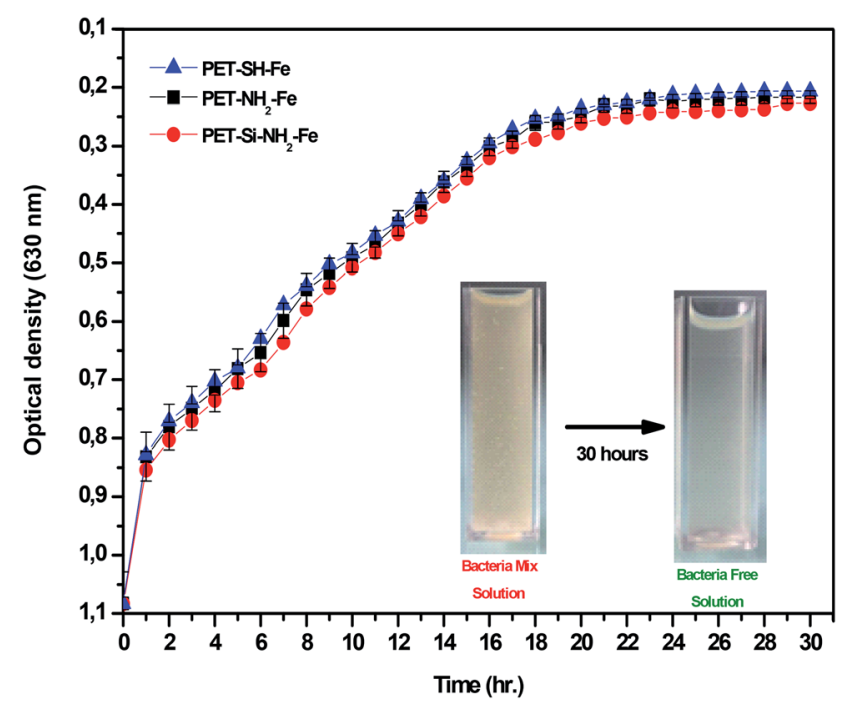

Fig. 18 Optical density analysis of antibacterial property of the membrane towards the mixture of Gram-positive and Gram-negative bacteria strains. 
Table 6 Kinetics analysis of antibacterial property of the membrane towards the mixture of Gram-positive and Gram-negative bacteria strains

\begin{tabular}{|c|c|c|c|}
\hline Sample & ${ }^{a}$ Time (h) & ${ }^{b} k\left(\min ^{-1}\right)$ & ${ }^{c} R^{2}$ \\
\hline PET-Si-NH ${ }_{2}-\mathrm{Fe}$ & 30 & $1.604 \times 10^{-2}$ & 0.74699 \\
\hline PET-NH ${ }_{2}-\mathrm{Fe}$ & 30 & $2.376 \times 10^{-2}$ & 0.84931 \\
\hline PET-SH-Fe & 30 & $2.398 \times 10^{-2}$ & 0.86305 \\
\hline
\end{tabular}

${ }^{a}$ Time provided for maximum inhibition. ${ }^{b} k$ is the rate constant and expressed in $\min ^{-1} .{ }^{c} R^{2}$ is the correlation coefficient of the linear regression.

Optical density analysis was also carried out to investigate the bacteria removal effectiveness of the membranes showed a precise and auspicious conclusion as reported in Fig. 18. The results showed that membranes prepared by both amine and thiol based cross-linkers can remove the bacteria from the solution. The removal efficiency was studied by calculating the kinetics obtained by UV-vis spectroscopic data (see Table 6).

It was found that the thiol (SH) based PET-SH-Fe membrane removed the maximum (average. 86\%) bacteria at $2.398 \times$ $10^{-2} \min ^{-1}$ which can reach up to $99.97 \%$ depending on the time and amount of catalyst used. The reason behind the higher effectiveness of the PET-SH-Fe membrane towards the catalytic activity (antibacterial effect) is due to the higher stability of the zerovalent iron nanoparticles evaluated by morphological, quantitative, thermal and size distribution analysis as discussed above.

\section{Conclusions}

This study set out to develop flexible multifunctional fibrous membrane for heterogeneous Fenton-like removal of organic and pathogenic contaminants from wastewater by immobilizing zerovalent iron nanoparticles (Fe-NPs) on PAMAM, APTES or 1-thioglycerol grafted polyester membranes. At initial activation, the eco-friendly plasma activation process of polyester was chosen. Wettability analysis through contact angle goniometry analysis revealed the successful activation of the polyester membrane. The contact angle reduced from $137^{\circ}$ to $0^{\circ}$ proved the integration of hydrophilic groups on the polyester surface due to plasma treatment.

SEM and FTIR analysis confirmed the grafting of PAMAM, APTES and $\mathrm{SH}$ and immobilization of iron nanoparticle on polyester membranes. Results revealed the effectiveness of the amine/thiol groups towards immobilization and stabilization of iron nanoparticles. Quantitative loading analysis of iron nanoparticles by using TGA analysis revealed the potentiality of the prepared material as a catalyst in Fenton-like reaction. The catalytic property studied for removal of crystal violet dye and inhibit the growth of $S$. epidermidis and $E$. coli bacteria strains reveal the effectiveness of the membranes as summarized below;

(a) The prepared catalyst showed significant $94-99 \%$ removal of crystal violet dye in 22-68 min depending on the type of membranes used (based on functionalization treatment). All catalysts showed significant reusability of 4-7 cycles during crystal violet removal without significant decrease in performance. Definite influences of $\mathrm{pH}$, amount of Fe and concentration of hydrogen peroxide has been concluded.

(b) The resulting materials PET-Si-NH $\mathrm{N}_{2}-\mathrm{Fe} \mid \mathrm{PET}-\mathrm{SH}-$ $\mathrm{Fe} \mid \mathrm{PET}-\mathrm{NH}_{2}-\mathrm{Fe}$ and PET-Fe turned out to have strong bactericidal activity against $S$. epidermidis and $E$. coli observed through disc diffusion and optical density analysis. Highest $86 \%$ inhibition of bacterial mix solution was observed for PET$\mathrm{SH}-\mathrm{Fe}$ in 30 hours of observation which are expected to be up to 99.99\% respect to time and concentration of the catalysts.

The overall results confirm the potential of flexible multifunctional fibrous membranes in bioremediation and green chemistry applications through rational design of robust catalyst capable of effective removal of organic and pathogenic contaminants in various environment.

\section{Conflicts of interest}

The authors claim no conflicts of interest.

\section{Acknowledgements}

This work has been comprehended in the framework of Erasmus Mundus Joint Doctorate Project-Sustainable Management and Design for Textiles (SMDTex), which is financed by the European Commission (grant no. 532704-EM-5-2017-1FRERA). The authors are very thankful to INSA Rouen, Rouen University, CNRS, Labex SynOrg (ANR-11-LABX-0029) for their support in characterization. The authors would also like to thank Mr Christian Catel from GEMTex Lab at ENSAIT, France and staff of Textile Material Technology lab at the University of Boras, Sweden for their support.

\section{References}

1 C. Singh, A. Goyal and S. Singhal, Nickel-doped cobalt ferrite nanoparticles: efficient catalysts for the reduction of nitroaromatic compounds and photo-oxidative degradation of toxic dyes, Nanoscale, 2014, 6(14), 7959-7970.

2 C. Fernández, M. S. Larrechi and M. P. Callao, An analytical overview of processes for removing organic dyes from wastewater effluents, TrAC, Trends Anal. Chem., 2010, 29(10), 1202-1211.

3 P. Kovacic and R. Somanathan, Nitroaromatic compounds: Environmental toxicity, carcinogenicity, mutagenicity, therapy and mechanism, J. Appl. Toxicol., 2014, 34(8), 810824.

$4 \mathrm{~J}$. Vieillard, et al., CuO Nanosheets Modified with Amine and Thiol Grafting for High Catalytic and Antibacterial Activities, Ind. Eng. Chem. Res., 2019, 58(24), 10179-10189.

5 A. K. Gupta, A. Pal and C. Sahoo, Photocatalytic degradation of a mixture of Crystal Violet (Basic Violet 3) and Methyl Red dye in aqueous suspensions using $\mathrm{Ag}+$ doped TiO2, Dyes Pigm., 2006, 69(3), 224-232.

6 A. Ivanets, et al., Effect of metal ions adsorption on the efficiency of Methylene Blue degradation onto $\mathrm{MgFe}_{2} \mathrm{O}_{4}$ as Fenton-like catalysts, Colloids Surf., A, 2019, 571, 17-26. 
7 T. Robinson, et al., Remediation of dyes in textile effluent: a critical review on current treatment technologies with a proposed alternative, Bioresour. Technol., 2001, 77(3), 247-255.

$8 \mathrm{Y}$. Wang, et al., Synthesis of flower-like $\mathrm{TiO}_{2}$ microsphere/ graphene composite for removal of organic dye from water, Mater. Des., 2016, 99, 378-388.

9 A. Azizi, M. Abouseoud and A. Amrane, Phenol Removal by a Sequential Combined Fenton-Enzymatic Process, Nat. Environ. Pollut. Technol., 2017, 16(1), 321.

$10 \mathrm{~S}$. Liang, et al., Rapid malachite green degradation using $\mathrm{Fe}_{73.5} \mathrm{Si}_{13.5} \mathrm{~B}_{9} \mathrm{Cu}_{1} \mathrm{Nb}_{3}$ metallic glass for activation of persulfate under UV-Vis light, Mater. Des., 2017, 119, 244253.

$11 \mathrm{H}$. Deb, et al., Immobilization of Cationic Titanium Dioxide (TiO 2+) on Electrospun Nanofibrous Mat: Synthesis, Characterization, and Potential Environmental Application, Fibers Polym., 2018, 19(8), 1715-1725.

$12 \mathrm{H}$. Deb, et al., Design and development of $\mathrm{TiO}_{2}-\mathrm{Fe}$ 0 nanoparticle-immobilized nanofibrous mat for photocatalytic degradation of hazardous water pollutants, J. Mater. Sci.: Mater. Electron., 2019, 30(5), 4842-4854.

13 M. N. Morshed, et al., Titania-loaded cellulose-based functional hybrid nanomaterial for photocatalytic degradation of toxic aromatic dye in water, J. Water. Process. Eng., 2020, 33, 101062.

14 A. Babuponnusami and K. Muthukumar, Degradation of phenol in aqueous solution by Fenton, sono-Fenton and sono-photo-Fenton methods, Clean: Soil, Air, Water, 2011, 39(2), 142-147.

15 D. Chen, et al., Heterogeneous Fenton-like catalysis of FeMOF derived magnetic carbon nanocomposites for degradation of 4-nitrophenol, RSC Adv., 2017, 7(77), 4902449030.

16 Y.-S. Ma, S.-T. Huang and J.-G. Lin, Degradation of 4nitrophenol using the Fenton process, Water Sci. Technol., 2000, 42(3-4), 155-160.

17 B. Nabil, et al., Polyfunctional cotton fabrics with catalytic activity and antibacterial capacity, Chem. Eng. J., 2018, 351, 328-339.

18 B. Nabil, et al., Development of new multifunctional filter based nonwovens for organics pollutants reduction and detoxification: High catalytic and antibacterial activities, Chem. Eng. J., 2019, 356, 702-716.

19 M. N. Morshed, et al., Stabilization of zero valent iron (Fe0) on plasma/dendrimer functionalized polyester fabrics for Fenton-like removal of hazardous water pollutant, Chem. Eng. J., 2019, 374, 658-673.

20 M. N. Morshed, et al., Iron-loaded amine/thiol functionalized polyester fibers with high catalytic activities: a comparative study, Dalton Trans., 2019, 48(23), 8384-8399.

$21 \mathrm{~N}$. Bouazizi, et al., Entrapment and stabilization of iron nanoparticles within APTES modified graphene oxide sheets for catalytic activity improvement, J. Alloys Compd., 2019, 771, 1090-1102.
22 G. C. Yang, H.-C. Tu and C.-H. Hung, Stability of nanoiron slurries and their transport in the subsurface environment, Sep. Purif. Technol., 2007, 58(1), 166-172.

23 F. He and D. Zhao, Preparation and characterization of a new class of starch-stabilized bimetallic nanoparticles for degradation of chlorinated hydrocarbons in water, Environ. Sci. Technol., 2005, 39(9), 3314-3320.

24 W. Wang, et al., Preparation of spherical iron nanoclusters in ethanol-water solution for nitrate removal, Chemosphere, 2006, 65(8), 1396-1404.

25 H. Kim, et al., Degradation of trichloroethylene by zerovalent iron immobilized in cationic exchange membrane, Desalination, 2008, 223(1-3), 212-220.

$26 \mathrm{H}$. Choi, et al., Synthesis of reactive nano-Fe/Pd bimetallic system-impregnated activated carbon for the simultaneous adsorption and dechlorination of PCBs, Chem. Mater., 2008, 20(11), 3649-3655.

27 M. N. Morshed, et al., Surface modification of polyester fabric using plasma-dendrimer for robust immobilization of glucose oxidase enzyme, Sci. Rep., 2019, 9(1), 1-16.

28 M. Montazer and V. Allahyarzadeh, Electroless plating of silver nanoparticles/nanolayer on polyester fabric using AgNO3/NaOH and ammonia, Ind. Eng. Chem. Res., 2013, 52(25), 8436-8444.

29 M. A. Miankafshe, T. Bashir and N.-K. Persson, The role and importance of surface modification of polyester fabrics by chitosan and hexadecylpyridinium chloride for the electrical and electro-thermal performance of graphenemodified smart textiles, New J. Chem., 2019, 43(17), 66436658.

30 N. Bouazizi, et al., Copper oxide coated polyester fabrics with enhanced catalytic properties towards the reduction of 4nitrophenol, J. Mater. Sci.: Mater. Electron., 2018, 29(13), 10802-10813.

31 F. Leroux, et al., Atmospheric air plasma treatment of polyester textile materials. Textile structure influence on surface oxidation and silicon resin adhesion, Surf. Coat. Technol., 2009, 203(20-21), 3178-3183.

32 A. Vesel, et al., Surface modification of polyester by oxygen-and nitrogen-plasma treatment, Surf. Interface Anal., 2008, 40(11), 1444-1453.

33 B. Nabi, et al., Inorganic-organic-fabrics based polyester/ cotton for catalytic reduction of 4-nitrophenol, J. Mol. Struct., 2019, 1180, 523-531.

$34 \mathrm{H}$. Lim, et al., Highly active heterogeneous Fenton catalyst using iron oxide nanoparticles immobilized in alumina coated mesoporous silica, Chem. Commun., 2006, (4), 463465.

35 H. Zhang, et al., Reduction Cooperated Fenton Oxidation of Zero-valent Iron (ZVI) Immobilized in Alginate Microsphere for Degradation of Acid Red B, Huanjing Kexue, 2019, 40(2), 708-716.

36 M. S. Mia, et al., Dopamine Grafted Iron-Loaded Waste Silk for Fenton-Like Removal of Toxic Water Pollutants, Polymers, 2019, 11(12), 2037.

37 V. Takke, et al., Studies on the atmospheric air-plasma treatment of PET (polyethylene terephtalate) woven fabrics: 
effect of process parameters and of aging, J. Appl. Polym. Sci., 2009, 114(1), 348-357.

38 F. Ajala, et al., Synthesis of Li-doped ZnO via sol-gel process: structural, optical and photocatalytic properties, J . Mater. Sci. : Mater. Electron, 2017, 28(3), 2817-2825.

39 A. Mohamed, et al., Activity of enzymes immobilized on plasma treated polyester, J. Mol. Catal. B: Enzym., 2016, 134, 261-272.

$40 \mathrm{~F}$. Z. Yehia, et al., Enhancement of the working $\mathrm{pH}$ range for degradation of p-nitrophenol using $\mathrm{Fe} 2+-$ aspartate and Fe2+-glutamate complexes as modified Fenton reagents. 25.2 (2016): 239-245., Egypt. J. Pet., 2016, 25(2), 239-245.

$41 \mathrm{~S}$. Tiwari, et al., Influence of cold remote nitrogen oxygen plasma treatment on carbon fabric and its composites with specialty polymers, J. Mater. Sci., 2011, 46(4), 964-974.

42 D. Shao and Q. Wei, Microwave-Assisted Rapid Preparation of Nano-ZnO/Ag Composite Functionalized Polyester Nonwoven Membrane for Improving Its UV Shielding and Antibacterial Properties, Materials, 2018, 11(8), 1412.

$43 \mathrm{X}$. Wang, et al., Different amine-functionalized poly (diphenylsubstituted acetylenes) from the same precursor, Polym. Chem., 2016, 7(33), 5312-5321.

44 A. Singh, et al., Highly facile and rapid one-pot synthetic protocol for the formation of Se nanoparticles at ambient conditions with controlled phase and morphology: role of starch and cytotoxic studies, Mater. Res. Express, 2018, 6(1), 015029.

$45 \mathrm{~J}$. Martínez, et al., Thioglycerol matrix interactions in the positive ion fast atom bombardment mass spectrometry of several Hantzsch and Biginelli ester derivatives of boronic acids, Rapid Commun. Mass Spectrom., 2013, 27(13), 15731578.

$46 \mathrm{Y} . \mathrm{Mu}$, et al., Iron oxide shell mediated environmental remediation properties of nano zero-valent iron, Environ. Sci.: Nano, 2017, 4(1), 27-45.

47 M. A. V. Ramos, et al., Simultaneous oxidation and reduction of arsenic by zero-valent iron nanoparticles: understanding the significance of the core-shell structure, J. Phys. Chem. $C, 2009,113(33), 14591-14594$.

48 R. W. Seymour, J. R. Overton and L. S. Corley, Morphological characterization of polyester-based elastoplastics, Macromolecules, 1975, 8(3), 331-335.

49 S. Mani and R. N. Bharagava, Exposure to crystal violet, its toxic, genotoxic and carcinogenic effects on environment and its degradation and detoxification for environmental safety, in Reviews of Environmental Contamination and Toxicology, vol. 237, 2016, Springer, pp. 71-104.

$50 \mathrm{~W}$. Au, et al., Cytogenetic toxicity of gentian violet and crystal violet on mammalian cells in vitro, Mutation Research/ Genetic Toxicology, 1978, 58(2-3), 269-276.

51 G. K. Cheruiyot, et al., Adsorption of Toxic Crystal Violet Dye Using Coffee Husks: Equilibrium, Kinetics and Thermodynamics Study, Scientific African, 2019, e00116.

$52 \mathrm{~K}$. Kwasniewska, Biodegradation of crystal violet (hexamethyl-p-rosaniline chloride) by oxidative red yeasts, Bull. Environ. Contam. Toxicol., 1985, 34(1), 323-330.
53 A. Mittal, et al., Adsorption of hazardous dye crystal violet from wastewater by waste materials, J. Colloid Interface Sci., 2010, 343(2), 463-473.

$54 \mathrm{M}$. Li, et al., Solvothermal synthesis of $\mathrm{Mn}_{\mathrm{x}} \mathrm{Fe}_{3-\mathrm{x}} \mathrm{O}_{4}$ nanoparticles with interesting physicochemical characteristics and good catalytic degradation activity, Mater. Des., 2016, 97, 341-348.

55 R. E. Palma-Goyes, et al., Electrochemical degradation of crystal violet with BDD electrodes: effect of electrochemical parameters and identification of organic by-products, Chemosphere, 2010, 81(1), 26-32.

$56 \mathrm{H}$. Zhang, et al., Electrochemical oxidation of Crystal Violet in the presence of hydrogen peroxide, J. Chem. Technol. Biotechnol., 2010, 85(11), 1436-1444.

57 F. Guzman-Duque, et al., Effects of sonochemical parameters and inorganic ions during the sonochemical degradation of crystal violet in water, Ultrason. Sonochem., 2011, 18(1), 440-446.

58 J. Liu, et al., Preparation of new adsorbent-supported $\mathrm{Fe} / \mathrm{Ni}$ particles for the removal of crystal violet and methylene blue by a heterogeneous Fenton-like reaction, RSC Adv., 2019, 9(39), 22513-22522.

59 L. Guz, et al., Adsorption of crystal violet on montmorillonite (or iron modified montmorillonite) followed by degradation through Fenton or photo-Fenton type reactions, J. Environ. Chem. Eng., 2014, 2(4), 2344-2351.

$60 \mathrm{~V}$. Vaiano, O. Sacco and D. Sannino, Electric energy saving in photocatalytic removal of crystal violet dye through the simultaneous use of long-persistent blue phosphors, nitrogen-doped $\mathrm{TiO}_{2}$ and UV-light emitting diodes, J. Clean. Prod., 2019, 210, 1015-1021.

61 F.-Y. Liu, et al., Lead bismuth oxybromide/graphene oxide: synthesis, characterization, and photocatalytic activity for removal of carbon dioxide, crystal violet dye, and 2hydroxybenzoic acid, J. Colloid Interface Sci., 2020, 562, 112-124.

62 B. A. Ünnü, G. Gündüz and M. Dükkancı, Heterogeneous Fenton-like oxidation of crystal violet using an iron loaded ZSM-5 zeolite, Desalin. Water Treat., 2016, 57(25), 1183511849.

63 R. Ullah, et al., Controlled crystal phase and particle size of loaded-TiO2 using clinoptilolite as support via hydrothermal method for degradation of crystal violet dye in aqueous solution, Arabian J. Chem., 2020, 13(2), 40924101.

64 A. Mehdinia, et al., High-efficient mercury removal from environmental water samples using di-thio grafted on magnetic mesoporous silica nanoparticles, Environ. Sci. Pollut. Res., 2015, 22(3), 2155-2165.

$65 \mathrm{~J}$. Aguado, et al., Aqueous heavy metals removal by adsorption on amine-functionalized mesoporous silica, $J$. Hazard Mater., 2009, 163(1), 213-221.

66 N. Bouazizi, et al., Silver nanoparticle embedded copper oxide as an efficient core-shell for the catalytic reduction of 4-nitrophenol and antibacterial activity, Dalton Trans., 2018, 47(27), 9143-9155. 
67 M. Wawrzkiewicz, et al., Adsorptive removal of acid, reactive and direct dyes from aqueous solutions and wastewater using mixed silica-alumina oxide, Powder Technol., 2015, 278, 306-315.

68 M. Orhan, D. Kut and C. Gunesoglu, Improving the antibacterial activity of cotton fabrics finished with triclosan by the use of 1,2,3,4-butanetetracarboxylic acid and citric acid, J. Appl. Polym. Sci., 2009, 111(3), 1344-1352.

69 E. Pinho, et al., Antimicrobial activity assessment of textiles: standard methods comparison, Ann. Microbiol., 2011, 61(3), 493-498.
70 S. Saqib, et al., Synthesis, characterization and use of iron oxide nano particles for antibacterial activity, Microsc. Res. Tech., 2018, 82(4), 415-420.

71 V. T. Trang, et al., APTES Functionalized Iron Oxide-Silver Magnetic Hetero-Nanocomposites for Selective Capture and Rapid Removal of Salmonella enteritidis from Aqueous Solution, J. Electron. Mater., 2018, 47(5), 2851-2860. 72 C. Lee, et al., Bactericidal effect of zero-valent iron nanoparticles on Escherichia coli, Environ. Sci. Technol., 2008, 42(13), 4927-4933. 